\title{
SPARK PLASMA SINTERING OF AGGLOMERATED VANADIUM CARBIDE POWDER
}

\author{
Wei Li ${ }^{a}$, Eugene A. Olevsky ${ }^{\star}, a, b, c$, Oleg L. Khasanov ${ }^{b, c}$, \\ Christina A. Back ${ }^{d}$, Oleg Izhvanov ${ }^{d}$, Jonas Opperman ${ }^{d}$, Hesham E. Khalifa ${ }^{d}$ \\ a Mechanical Engineering Department, San Diego State University \\ 5500 Campanile Drive, San Diego, CA 92182-1326, USA \\ ${ }^{b}$ Engineering Physics University, Moscow, 115409, Russia \\ 'National Research Tomsk Polytechnic University, Tomsk, 634050 Russia \\ ${ }^{d}$ General Atomics, 3550 General Atomics Court, San Diego, CA 92121 USA
}

\begin{abstract}
Spark plasma sintering (SPS) is an emerging powder consolidating technique which promises high potential capabilities to process refractory ceramics with properties previously unattainable. As the first step in studying the applicability of this technique to the processing of tailored ceramic structures, the validity of SPS to consolidate refractory carbides with controllable porosity is investigated. Vanadium carbide $\left(\mathrm{V}_{8} \mathrm{C}_{7}\right)$ is chosen as a studied material. The structure, thermal and mechanical properties of the $\mathrm{V}_{8} \mathrm{C}_{7}$ powder pellets produced by SPS are analyzed and discussed in the paper. The attained properties of the processed ceramic material are in particular suitable for applications where high electrical conductivity and strength at high melting temperatures, low thermal conductivity and low thermal expansion coefficient are needed.
\end{abstract}

Keywords: Vanadium carbide; spark plasma sintering; thermal and mechanical properties

"Corresponding author email: eolevsky@mail.sdsu.edu 


\section{Introduction}

In most industrial applications, a major task of powder processing, including Spark-Plasma Sintering (SPS) technology, is to create a product with maximum possible density. Use of conventional consolidation techniques to achieve these goals presents challenges. Refractory carbide materials are difficult to consolidate because of their high melting temperatures. In addition, long dwell times at high temperatures, which are typically necessary to consolidate powders, tend to produce larger grains, - a disadvantage for various applications where mechanical properties of the final products are important. Furthermore, consolidation techniques are more commonly developed to reduce porosity by using additives and binders to facilitate densification, which would generally be detrimental for further performance of the produced components.

The emerging spark plasma sintering technology looks promising for the fabrication of stable porous ceramic structures [1,2]. More effective densification over conventional sintering is expected due to a number of SPS-induced effects: high heating rates, which may enable higher sinterability; high local temperature gradients, which provide conditions for thermal diffusion; highly non-uniform local temperature distributions, which may cause melting at inter-particle contacts.

Processing of vanadium carbide powder has been analyzed only to a limited extent, although this material possesses a number of useful refractory and resistive properties. Most of research works related to consolidation of VC by pressing and sintering utilized it as a complementary material only [3-13].

An interesting application is the employment of vanadium carbide $\left(\mathrm{V}_{8} \mathrm{C}_{7}\right)$ as a surrogate material for uranium carbide to investigate the potential of spark 
plasma sintering as a hot consolidation technique to densify the carbide fuel pellets. Spark plasma sintering devices are now starting to find applications for fabrication of nuclear fuels. Recent publications have focused on $\mathrm{UO}_{2}$ [14].

For nuclear applications, a fuel pellet that efficiently vents fission gases may be expected to have a significant (20-30\%) fraction of connected pores in the fuel material to allow fission products to escape from the fuel pellet to a plenum in the fuel rod where the gases can then be removed [15]. However, any porous fuel pellet must have sufficient strength to withstand manufacturing operations and inservice thermal stresses without losing its integrity. One example of a pellet microstructure arrangement being explored for a gas-cooled fast reactor called "the Energy Multiplier Module, $\mathrm{EM}^{2}$ ", is a bi-porous structure formed by sintering spherical fuel kernels (see Figure 1) [16]. This structure would have a fuel kernel internal porosity and inter-kernel porosity with controlled, connected flow paths for the fission product gases to escape. The inter-particle pores would provide void volume for the accommodation of the fuel swelling by creep. The target porosity for this pellet is around $25 \%$. To remain intact over the lifetime of the fuel, the pellet must sustain thermal stresses of the order of $60 \mathrm{MPa}$ according to calculations [16]. Since material strength is highly temperature dependent, high thermal conductivity is required to maintain the structure temperature within the designed limit for strength retention purposes. Typical fuel structure requires thermal conductivity above $3 \mathrm{~W} /(\mathrm{m} \cdot \mathrm{K})$ at $800^{\circ} \mathrm{C}$ operation temperature [17]. The basic desired properties for carbide-based nuclear fuel pellet according to General Atomics' design [16] are summarized in Table 1. 
Study of surrogate material processing is very important for nuclear related materials such as uranium carbide, because a well selected surrogate can significantly reduce the environmental impact and cost during the development stage while still obtaining meaningful results for the actual fuel fabrication $[18,19]$. $\mathrm{V}_{8} \mathrm{C}_{7}$ has exactly the same cubic-cF8 crystal structure, Fm $3 \mathrm{~m}$ No. 225 space group, as UC, and thus shares similar mechanical properties that affect consolidation. In addition, the melting temperature of $\mathrm{V}_{8} \mathrm{C}_{7}$ is the closest amongst all the refractory carbides to that of UC, - an important consideration when studying the sintering behavior. The physical properties of vanadium carbide are summarized in Table 2 [20-25]. It should be also noted that, according to the reported property summary for vanadium carbide (Table 2) and comparing it to typical metal based materials (such as aluminum, copper, and silver-based etc.), vanadium carbide has low thermal conductivity and thermal expansion coefficient, but high electrical conductivity and ultra-high melting temperature. In particular, the higher melting temperature and lower electrical conductivity, relative to that of UC, make it a good candidate for assessing an upper boundary temperature necessary for consolidation of UC by SPS.

The advantage of SPS has been demonstrated by a paper that reported free sintering results for the same vanadium carbide powder used in the present study [26]. In that study, a green vanadium carbide pellet was cold pressed up to $52 \%$ relative density, and then consolidated using a $10^{\circ} \mathrm{C} / \mathrm{min}$ heating rate up to $1550^{\circ} \mathrm{C}$ (maximum allowable alumina tube-based dilatometer temperature) followed by a 3 hours dwell time in vacuum (10 Pa). Under these temperatures, significantly lower than the respective melting temperature, the final sintered 
density was not changed at all from the density obtained under cold pressing. The authors found that it was impossible to densify binder-free vanadium carbide by conventional sintering at the above-mentioned temperature of $1550^{\circ} \mathrm{C}$ [26].

In the present paper, spark plasma sintering is evaluated in terms of its efficiency to consolidate carbide materials, create porous structures, and achieve sufficient product strength. In addition to the advantageous densification effects mentioned above, SPS is also selected as a processing technique because it has demonstrated the potential to reduce fabrication time, retain small grain size, and create structures with higher strength due to the enhanced SPS neck-growth kinetics.

The present paper is organized as follows. Section 2 describes the materials, processing and testing in the framework of the conducted research to successfully consolidate additive-free (binder-free) vanadium carbide. In Section 3 , the results of the characterization of the density, microstructure, and composition phases of the vanadium carbide pellets processed by SPS, porosity, and permeability are provided. The measured physical properties including transverse rupture strength, hardness, volume specific constant pressure heat capacity, and thermal conductivity are also reported in Section 3 . Section 4 includes the overall discussion of the research results.

\section{Materials and Experimentation}

\subsection{Materials Processed by Spark-Plasma Sintering}

For these studies, raw material having a nominal particle size similar to that expected for the fuel kernels was obtained from the vendor Changsha Asian 
Light Economic Trade Co., Ltd. Its powder characteristics are reported in Table 3. After processing by the vendor, which included dry milling in a WC-Co container by WC balls, the vanadium carbide $\left(\mathrm{V}_{8} \mathrm{C}_{7}\right)$ was a mixture of powder ranging in size from 5 to $10 \mu \mathrm{m}$ and of agglomerated irregular particles roughly 200 to $300 \mu \mathrm{m}$ in size (see Figure 2).

A laser diffraction particle size and image analyzer (S3500SI, Microtrac, Nikkiso, Japan) was used to characterize the particle size distribution for different powders. The laser used in the micro-size detector had a wavelength of $405 \mathrm{~nm}$. $10 \%$ of nonionic hydrophilic surfactant Triton $X 100$ was added to the deionized water to disperse the powders effectively and then test them in the wet mode. Before the powder entering into the laser chamber, further dispersion by ultrasonic vibration at 40 Watts for 60 seconds was applied to guarantee obtaining the accurate particle size distribution. The particle size distribution measurement results are shown in Figure 3.

The material composition was identified by both combustion and X-Ray diffraction (XRD) methods. Combustion analysis measured oxygen content of 0.16 wt.\%. X-Ray fluorescent analysis revealed Ti, Fe, Ni, Ge, Ca, Al impurities at the level from 0.1 to $0.3 w t . \%$. To determine the characteristic phase after sintering, X-ray diffraction (Panalytical, XPert Pro MRD) was performed on the pellets. The XRD analysis was performed using the following configuration: copper target, K-Alpha band (1.54 Am), and generator setting of $40 \mathrm{~mA}$ at $45 \mathrm{kV}$. These measurements identified the phase of the vanadium carbide powder to be a stoichiometry of $\mathrm{V}_{8} \mathrm{C}_{7}$. The results are plotted in Figure 4 . 


\subsection{Consolidation of Vanadium Carbide Powder}

Experiments were performed using a spark-plasma sintering apparatus (Dr. Sinter 515 SPS, Fuji Electronics Industrial Co, Ltd., Japan) with pulse duration of 3.3 ms. A machine pulse sequence consisting of twelve pulses (39.6 ms) followed by two periods (6.6 ms) of zero current was chosen and termed 12:2. First the ball-milled powder mixture was prepared in pellet form with a tap density of $1.97 \mathrm{~g} / \mathrm{cm}^{3}(34 \%)$. Pellets of $15 \mathrm{~mm}$ in diameter and 4.00 gram in mass were then placed in vacuum, under uniaxial mechanical pressures of $20,25,60$, or 75 $\mathrm{MPa}$, applied from room temperature, and held constant until the end of the consolidation period.

The heating rate was set to $100^{\circ} \mathrm{C} / \mathrm{min}$, which enabled high efficiency consolidation cycle while avoiding the undesired localized inhomogeneous overheating. The following hot consolidation sequence has been used: (i) four minutes to heat from room temperature up to $580^{\circ} \mathrm{C}$, and then one minute was given to increase the temperature from $580^{\circ} \mathrm{C}$ to $700^{\circ} \mathrm{C}$ to achieve a stabilized temperature condition; (ii) heating with the rate of $100^{\circ} \mathrm{C} / \mathrm{min}$ from $700^{\circ} \mathrm{C}$ to the final hot consolidation temperature $\left(T_{F}\right)$ and dwelling during time periods of 5,10 , 15 or $30 \mathrm{~min}$ at this temperature; (iii) an on/off pulse sequence of 12:2 was utilized; (iv) vacuum condition of about $50 \mathrm{~Pa}$ was used for all the experiments from the processing beginning till the end. At the end of the dwelling time, the current was shut down, yielding a cooling rate of about $300^{\circ} \mathrm{C}$ from $\mathrm{T}_{\mathrm{F}}$ down to around $600^{\circ} \mathrm{C}$. Another $30 \mathrm{~min}$ were reserved for cooling the pellet specimen to room temperature, and then the applied mechanical pressure was released afterwards. 
The tooling and the pellet configuration are shown in Figure 5. The temperature was measured by an optical pyrometer focused on the surface of the graphite die and automatically regulated from $580^{\circ} \mathrm{C}$ up to the final sintering temperatures of $1100,1200,1300$ or $1400^{\circ} \mathrm{C}$.

The experiments were performed over specified ranges of pressures and temperatures to determine the relationship between porosity and processing conditions.

\subsection{Characterization of Processed Specimens}

The characterization of the spark-plasma sintered vanadium carbide pellets consisted of the density measurements, microstructural analysis using Scanning Electron Microscopy (SEM), the determination of characteristic phases using $\mathrm{XRD}$, porosity measurement by pycnometry, mechanical properties' measurements including transverse rupture strength and scale A Rockwell hardness, thermal properties' measurements including constant pressure specific heat capacity and thermal conductivity .

Since the porosity of the processed pellets was relatively high $(>8 \%)$, the Archimedean immersion method was difficult to apply. The density of the vanadium carbide pellet specimens was measured by geometry method (accurate for a regular cylindrical pellet specimen shape). The pellet specimens were weighed three times on a high accuracy scale (resolution $\pm 0.0001 \mathrm{~g}$ ); the diameter and height of the cylindrical pellet specimens were measured at three different locations; and the average density was calculated accordingly. 
For the microstructural observations using SEM, the pellet surfaces were polished with successively smaller grinding medium down to $0.04 \mu \mathrm{m}$ of colloidal silica. Grain boundary relief was produced by deep etching of $\mathrm{V}_{8} \mathrm{C}_{7}$ pellet in the mixed $\mathrm{HCl}-\mathrm{HNO}_{3}-\mathrm{HF}(10: 20: 10 \mathrm{ml})$ solution for 16 hours. Using the secondary electron mode in FE-SEM (FEI Quanta 450), micrographs of vanadium carbide pellets were obtained and the average grain size was estimated from each micrograph by the line intercept method [27]. In some cases the electron backscatter diffraction was used to confirm the measured grain size.

\subsection{Mechanical Property Measurement}

To test the mechanical strength of porous structures, a customized Transverse Rupture Strength (TRS) procedure based on the modified ASTM C1499-09 Standard [28] was developed. This procedure makes the approach more versatile for a range of pellet specimen sizes, particularly for difficult-tomachine materials like VC and processes like SPS where the processed specimen diameter is determined by the die size. The details of this testing method were firstly described in the listed reference [29]. The TRS loading rate configuration is: $0.001 \mathrm{in} / \mathrm{sec}(0.0254 \mathrm{~mm} / \mathrm{sec})$, on a conventional material testing frame (Model 5982, Instron, MA) with CMP 10V tool steel fixture set and $3 \mathrm{~mm}$ diameter WC indenter ball.

Transverse rupture strength of SPS-processed specimens is determined as:

$$
\sigma_{T R S}=\frac{F}{h^{2}}\left[(1+v)\left(0.485 \log _{10} \frac{r_{e}}{h}+0.52\right)+0.48\right] \quad \text { Equation } 1
$$

where $\sigma_{T R S}$ is the equivalent TRS value in $\mathrm{MPa}, F$ is the load in $\mathrm{N}, v$ is the Poisson's ratio (for $\mathrm{VC}$ is 0.35 ), $r_{e}$ is the effective radius of a disk-shape sample 
(6.5 $\mathrm{mm}$ in the present tooling fixture), and $h$ is the average thickness of the diskshape sample in $\mathrm{mm}$.

Olevsky had derived the Poisson's ratio for a porous material as follows [30]:

$$
v_{p}=\frac{2-3 \theta}{4-3 \theta}
$$

Equation 2

where $v_{p}$ is the Poisson's ratio for a porous material, $\theta$ is porosity. The above expression was derived for perfect isotropic material with Poisson's ratio of 0.5 (when porous material skeleton is incompressible). In the present work the relative Poisson's ratio [31] (normalized to show the dependence on porosity) is employed:

$$
R_{N}=\frac{v_{p}}{v_{p i}}=2\left(\frac{2-3 \theta}{4-3 \theta}\right)
$$

Equation 3

where $R_{N}$ is the relative or normalized Poisson's ratio, $v_{p i}$ is the Poisson's ratio for incompressible isotropic materials (equal to 0.5). Then the actual Poisson's ratio for a porous material with a compressible substance material can be calculated as:

$$
v=v_{0} R_{N}=2 v_{0}\left(\frac{2-3 \theta}{4-3 \theta}\right)
$$

Equation 4

where $v_{0}$ is the Poisson's ratio for fully dense bulk materials, and $v$ is the general material Poisson's ratio that is used for the transverse rupture strength calculation.

\subsection{Thermal Properties' Measurement}

Vanadium Carbide constant pressure specific heat capacity and thermal conductivity were measured using Netzsch Differential Scanning Calorimeter 
(DSC) 404 F1 Pegasus and Laser Thermal Flash Analyzer (LTFA) 427, respectively. The measurements were performed on various $\mathrm{V}_{8} \mathrm{C}_{7}$ specimens processed under different SPS conditions. The constant pressure specific heat capacity was determined by the differential ratio method using a sapphire standard. The constant pressure specific heat capacity data were used along with the thermal diffusivity data to determine thermal conductivity. All thermal analysis measurements have been conducted between room temperature and $1100^{\circ} \mathrm{C}$ in argon atmosphere.

There are two other important observations for the obtained constant pressure heat capacity data. One is that constant pressure specific heat capacity is higher at higher temperatures before phase transformation takes place. The other observation is that at around $1000^{\circ} \mathrm{C}$, the constant pressure heat capacity reached a peak point and then decreased sharply. This is associated with the exothermal phase transformation from ordered to disordered state occurring within the vanadium carbide structure. Debye temperature is not reported for this material system so far [32].

In the laser flash method, the derivation of thermal diffusivity and constant pressure specific heat capacity, are based on the measurement of the rising temperature on the back surface of a sample caused by a pulsed laser beam on the sample's front surface. The measurement is performed at each temperature point and the thermal conductivity at each temperature is calculated by using the following equation:

$$
k_{t c}=\alpha \rho C_{P}
$$

\section{Equation 5}


where $k_{t c}$ is the thermal conductivity, $\alpha$ is the thermal diffusivity, $\rho$ is the processed specimen density, $C_{P}$ is the constant pressure specific heat capacity.

The thermal diffusivity is given by the following equation:

$$
\alpha=0.1388 \frac{L^{2}}{t_{\frac{1}{2}}} \quad \text { Equation } 6
$$

where $\alpha$ is the thermal diffusivity, $L$ is the thickness of the sample, $t_{1 / 2}$ is the time of the half maximum (the time for the rear surface temperature to reach $50 \%$ of its maximum value).

The constant pressure specific heat capacity $C_{P}$ determined by DSC, is given by the following equation:

$$
C_{P}=\frac{m_{\text {Standard }}}{m_{\text {Sample }}} \cdot\left(\frac{Q_{\text {Sample }}-Q_{\text {Baseline }}}{Q_{\text {Standard }}-Q_{\text {Baseline }}}\right) \cdot C_{p, \text { Standard }} \quad \text { Equation } 7
$$

where $m$ is the mass, $Q$ represents the energy of the DSC measured heat, and $C_{p, \text { standard }}$ is the constant pressure specific heat capacity for the standard reference (in this study, sapphire was used).

Measurement results for porosity, permeability, mechanical and thermal properties and data are described in Section 3.

\section{Processed Vanadium Carbide Pellets' Characterization Results}

\subsection{Structure Characterization Results}

The conducted tests indicate that, given a well-controlled SPS process, the desired pellet density (around 75\%) can be achieved for the utilized VC agglomerated powder. The measured relative density data obtained for various SPS conditions are listed in Table 4. 
Figure 6 shows an example of the sintering curves for two different pressures at the $1100^{\circ} \mathrm{C}$ consolidation temperature. As can be ob served, there is softening and then a roughly linear densification after 600 seconds (with temperature of about $1100{ }^{\circ}$ ). Figure 7 shows the densification kinetics for the $60 \mathrm{MPa}$ runs. For every $100{ }^{\circ} \mathrm{C}$ increment in temperature, a relative increase of $3.5-4 \%$ in density occurs. The data from Table 4 are selectively plotted in the form of a diagram (see Figure 8) to further explore the trend of the consolidated relative density dependence on temperature, pressure, and dwelling time. It is observed that higher temperature, longer dwelling time and higher mechanical stress generally produce specimens with higher relative density, as expected.

Figure 9 reveals the grain size and pore size distribution in the processed vanadium carbide SPS pellets. The observed grain size falls within the range of 10 to $15 \mu \mathrm{m}$ without significant growth for low to high density specimens. However, the reduction of the pore size is obvious as seen in Figure 9. In the achieved relative density range, the grain growth is very slow due to the grain boundary pinning effects imposed by the relatively large amount of pores. The initial agglomeration in the green powder disappears after SPS consolidation. The sintered grain size standard deviation is in a much smaller range $( \pm 10 \mu \mathrm{m})$ comparing to the starting powder $( \pm 100 \mu \mathrm{m})$ indicating no bimodal distribution characteristics.

In some SEM images, deep etching did not clearly reveal detailed grain structure, as in Figure 10 (a), so electron backscatter diffraction (EBSD) technique was used as a cross check. Figure 10 (a) and (b) show a comparison of the same surface area of the sample consolidated at $1300^{\circ} \mathrm{C}, 60 \mathrm{MPa}$, for 30 
min, with $79.8 \%$ relative density, characterized by SEM and EBSD technique, respectively. Different colors reflect transition from grain to grain and make grain size calculations easier. As it can be seen, EBSD images confirm grain size to be within scattering range of 8-12 $\mu \mathrm{m}$.

$\mathrm{XRD}$ analysis was used to determine the characteristic phases before and after SPS processing. Figure 11 shows the XRD pattern for the green powder and a pellet with $84.3 \%$ relative density sintered at temperature of $1400^{\circ} \mathrm{C}$ under $75 \mathrm{MPa}$ pressure with 30 min dwelling time.

The crystal structure characteristic peaks for the powder and the consolidated pellet match very well indicating that the SPS process did not change the vanadium carbide powder dominant phase present at room temperature. However, this does not mean that there was no phase change at high temperature during hot consolidation. Inspections of the constant pressure heat capacity data (see Figure 16) and of the phase diagram reported in Ref. [8] indicate that there is a phase transformation from ordered to disordered structure around $1000^{\circ} \mathrm{C}$. However, measurements show that after cooling to room temperature, the sintered pellet returns to its original phase composition.

Porosity in the structure consists of two types, open porosity and closed porosity. Pycnometer [33] was used to measure the closed porosity of the porous structure, and volumetric method was used to measure and calculate the total porosity.

Total Porosity $=100 \%$ - Relative Density $=$ Open Porosity + Close Porosity With the equation above, one can determine the fraction of open porosity within total porosity [34]. The correlation between open porosity and relative density is 
plotted in Figure 12. The data are available only for relatively low density range (60 to $65 \%$ ). In this range, open porosity contributes up to $90 \%$ of the total porosity.

Air was used as the pressurization gas to measure the permeability. The permeability test was conducted in the differential pressure range from 0 up to $100 \mathrm{kPa}$.

The average permeability versus different relative density is plotted in Figure 13. The permeability of porous structure drops as the relative density increases. Still, at density of $72 \%$, the permeability is as high as 0.6 Darcy.

\subsection{Mechanical and Thermal Property Measurement Results}

\subsubsection{Mechanical Properties of Processed Specimens}

The mechanical properties for selected pellets are plotted in Figure 14. In this graph, the data on four additional vanadium carbide pellets processed by traditional hot pressing are also included for comparison to cross check the TRS dependence on relative density. These hot pressing pellets data were obtained with the following processing parameters: peak temperature of $1400^{\circ} \mathrm{C}$, heating rate of $14^{\circ} \mathrm{C} / \mathrm{min}$, uniaxial pressure of 20,26 or $28 \mathrm{MPa}$, and dwelling time of 30 $\min$.

It is found that higher TRS strength and hardness are associated with higher relative density. The TRS of vanadium carbide pellets is found to have a linear dependence on relative density.

The processed specimens were polished to 1000 grit SiC paper surface finish for conducting the hardness measurements. 


\subsubsection{Thermal Properties of Processed Specimens}

Constant pressure specific heat capacity was found to increase with increasing relative density (see Figure 16). For a given volume, the higher relative density specimen has more substance (less voids) which requires more heat per degree of temperature increase. However, it should be noticed that samples sintered under different loads and for different times to similar densities show very similar constant pressure specific heat capacity. Therefore it is concluded that the different SPS processing could yield different bulk densities, but vastly different processing conditions used to achieve the same density do not produce an identifiable difference in constant pressure specific heat capacity.

By multiplying thermal diffusivity with constant pressure specific heat capacity, thermal conductivity was calculated and plotted in Figure 17. 


\section{Discussion}

The sintered vanadium carbide specimens show desirable relative densities as listed in Table 4. The achieved density covers the range between 57.5 to $84.3 \%$ (consolidated from the loose powder packing density of $34.1 \%$ ). It is noticed that if the hot consolidation temperature is not higher than $1100^{\circ} \mathrm{C}$, the achieved densification will not be larger than $10 \%$ regardless of the applied mechanical pressure and dwelling time (maximum allowable for the specific graphite tooling and SPS device). Therefore, $1100^{\circ} \mathrm{C}$ is identified as the threshold temperature for SPS hot consolidation of the studied vanadium carbide powder.

Since vanadium carbide has higher melting temperature and mechanical moduli than uranium carbide [22], the SPS conditions utilized in the current research should be powerful enough to consolidate the uranium carbide powder or kernel into fuel pellets with the desired density. Regarding the vanadium carbide material, its excellent thermal and electrical properties at high temperatures make it very attractive for further exploration. The conducted research shows that, if the high end of the SPS temperature capability is used, it 
should be feasible to consolidate vanadium carbide into near fully dense bulk materials for more advanced applications, such as electrodes for high temperature and corrosive environment and the core module components of thermoelectric conversion systems [35].

$\mathrm{XRD}$ analysis reveals that the characteristic phase of the SPS-processed vanadium carbide specimens is the same as of the starting vanadium carbide powder. However, this does not mean there is no reversible phase transformation at high temperatures.

The investigated mechanical properties of the processed vanadium carbide specimens included the measurements of the transverse rupture strength (TRS) and hardness. This is the first time that the TRS results are reported for binderfree vanadium carbide bulk material with different relative density levels. Comparing to the $97 \%$ near fully dense binder-free tantalum carbide TRS of 372 $\mathrm{MPa}$ [36], the measured porous structure properties look promising. Regarding the hardness, the $75.7 \%$ relative density pellet specimen achieved the hardness at $64 \%$ of the fully dense vanadium carbide value. Overall the SPS is found to have very good potential for producing binder-free carbide porous structures.

The thermal properties of SPS-processed vanadium carbide pellets were found to be dependent on the relative density (see Figure 16 and Figure 17). The constant pressure specific heat capacity for all the processed specimens show a sharp spike at temperature around $1000^{\circ} \mathrm{C}$, which is an indication of high temperature phase change with a potential order to disorder transformation [24]. Both the constant pressure specific heat capacity and thermal conductivity are found to be higher at higher temperatures. The phase transformation leads to 
stoichiometry change from $\mathrm{V}_{8} \mathrm{C}_{7}$ to $\mathrm{VC}_{\mathrm{y}}$ (with $\mathrm{y}$ in the range of 0.66 to 0.88 ). The impacts of the associated material property changes due to this phase transformation are very difficult to predict due to the lack of reported or measured high temperature treatment results. The challenge is associated not only with the complexity and metastable structure of the carbide at high temperatures, but also with the significant difficulties and high costs of test setups for elevated temperature treatments [37]. However, it is worth noticing that the exothermic phase transformation may cause carbon precipitation from carbide structure and increase the temperature within the structure temporarily, which may possibly compromise the strength of the fabricated materials.

Overall, by considering the requirements for a potential carbide fuel pellet, the SPS conditions which can render surrogate structures with satisfactory properties are summarized in Table 5.

\section{Conclusions}

This paper represents the first report of the bulk consolidation of a vanadium carbide powder material and of the processed specimens' measured mechanical and thermal properties. The major findings can be summarized as follows:

a. SPS demonstrated capability to consolidate vanadium carbide powder specimens up to a wide range of final densities (57.5 to $84.3 \%$ ), and the final density can be controlled through SPS process temperature, pressure or time, while the conventional dilatometer sintering is incapable to achieve any densification during three hours long processing. The identified SPS consolidation threshold temperature is at $1100^{\circ} \mathrm{C}$. 
b. The initial powder agglomerates of very fine particles collapsed and were condensed without observable grain growth under SPS consolidation regimes.

c. An improved approach to determine the transverse rupture strength for porous materials has been introduced by taking into consideration the Poisson's ratio dependence on porosity.

d. The obtained mechanical properties of the processed vanadium carbide specimens include: transverse rupture strength of $171 \mathrm{MPa}$ at $75.7 \%$ relative density, and hardness of HRA 84 at $79.4 \%$ relative density.

e. Different processing conditions used to achieve the same density do not yield an identifiable difference in constant pressure specific heat capacity and thermal conductivity. The achieved highest thermal conductivity is for pellets of $84.3 \%$ relative density, with assessed values from $15 \mathrm{~W} /\left[\mathrm{m}={ }^{\circ} \mathrm{C}\right]$ at $100^{\circ} \mathrm{C}$ to $26 \mathrm{~W} /\left[\mathrm{m} \cdot{ }^{\circ} \mathrm{C}\right]$ at $1000^{\circ} \mathrm{C}$.

Overall, this study shows that SPS can consolidate a refractory carbide powder with controllable final porosity. Generally, the high electrical conductivity and ultra-high melting temperature of vanadium carbide can make it very suitable as a high temperature conductor, especially for the applications in the thermoelectric conversion systems [35].

For application to nuclear fuels, the successful consolidation of vanadium carbide with densities spanning the range of 58 to $84 \%$, provides high confidence that uranium carbide can be also consolidated with controlled porosity. The objectives to produce refractory carbide porous ( $75 \%$ of the theoretical density) ceramic structure with sufficient (60 MPa) mechanical strength and high fraction of open porosity, while retaining average grains size and stoichiometry of the 
original agglomerated powder, were achieved. Also, the measured 0.6 Darcy value of permeability allows for a pressure drop that is orders of magnitude better than that needed for the venting of fission gas in an $\mathrm{EM}^{2}$ reactor fuel pellet. Obtaining these results at temperatures 44 to $54 \%$ of the melting temperature would eliminate the need for costly processing in high temperature $\left(>2000{ }^{\circ} \mathrm{C}\right)$ furnaces.

\section{Acknowledgements}

The support of the US Department of Energy, Materials Sciences Division, under Award No. DE-SC0008581 is gratefully acknowledged.

\section{References}

[1]. M.S. Yurlova, V.D. Demenyuk, L.Yu. Lebedeva, D.V. Dudina, E.G. Grigoryev, E.A. Olevsky, Electric pulse consolidation: an alternative to spark plasma sintering, J. Mater. Sci. 49 (2014) 952-985.

[2]. E.A. Olevsky, E.V. Aleksandrova, A.M. Ilyina, D.V. Dudina, A.N. Novoselov, K.Y. Pelve, E.G. Grigoryev, Outside mainstream electronic databases: review of studies conducted in USSR and post-soviet countries on electric current-assisted consolidation of powder materials. Materials 6 (2013) 4375-4440.

[3]. F.J. Arenas, A. Matos, M. Cabezas, C. Di Rauso, C. Grigorescu, Densification, mechanical properties and wear behavior of WC-VC-Co-Al hardmetals, Int. J. Refract. Met. Hard. Mater. 19 (2001) 381-387.

[4]. D.F. Carroll, Sintering and microstructural development in WC/Co-based alloys made with superfine WC powder, Int. J. Refract. Met. Hard Mater. 17 (1999) 123-132.

[5]. N.G. Hashe, S. Norgren, H.O. Andrén, J.H. Neethling, P.R. Berndt, Reduction of carbide grain growth in WC-VC-Co by sintering in a nitrogen atmosphere, Int. J. Refract. Met. Hard Mater. 27 (2009) 20-25. 
[6]. S.G. Huang, K. Vanmeensel, O. Van Der Briest, J. Vleugels, Binderless WC and WC-VC materials obtained by pulsed electric current sintering. Int. J. Refract. Met. Hard Mater. 26 (2008) 41-47.

[7]. H.R. Lee, D.J. Kim, N.M. Hwang, D.Y. Kim, Role of vanadium carbide additive during sintering of WC-Co: mechanism of grain growth inhibition, J. Amer. Ceram. Soc. 86 (2003) 152-54.

[8]. J. Poetschke, V. Richter, Influence and effectivity of VC and $\mathrm{Cr} 3 \mathrm{C} 2$ grain growth inhibitors of sintering of binderless tungsten carbide, Int. J. Refract. Met. Hard Mater. 31 ( 2012) 218-223.

[9]. J. Zou, G.J. Zhang, Y.M. Kan, P.L. Wang, Pressureless densification of $\mathrm{ZrB}_{2}$-SiC composites with vanadium carbide, Scripta Mater. 59 (2008) 309-312.

[10]. W. Yisan, D. Yichao, W. Jing, C. Fengjun, S. Jianguo, In situ production of vanadium carbide particulates reinforced iron matrix surface composites by cast-sintering, Mater Des. 28 (2007) 2202-2206.

[11]. R. Sepùlveda, F. Arenas, TiC-VC-Co: a study on its sintering and microstructure. Int. J. Refract. Met. Hard Mater. 19 (2001) 389-396.

[12]. L. He, Y. Liu, B. Li, H. Cao, J. Li, Reaction synthesis of in situ vanadium carbide particulates-reinforced iron matrix composites by spark plasma sintering, J. Mater. Sci. 45 (2010) 2538-2542.

[13]. P. Feng, Y. He, Y. Xiao, W. Xiong, Effect of vc addition on sinterability and microstructure of ultrafine $\mathrm{Ti}(\mathrm{C}, \mathrm{N})$-based cermets in spark plasma sintering, J. Alloys Comp. 460 (2008) 453-459.

[14]. L.H. Ge, R.H. Baney, J.S. Tulenko, E. McKenna, Densification of uranium Dioxide Fuel Pellets Prepared by Spark Plasma Sintering, J. Nucl. Mater. 435 (2013) 1-9.

[15]. G.L. Hofman, L.C. Walters, T.H. Bauer, Metallic Fast Reactor Fuels, Prog. in Nucl. Energy 31 (1997) 83-110.

[16]. R. Schlecher, C. Back, Configuring EM2 to meet the challenges of economics, waste disposition and non-proliferation confronting nuclear energy in the U.S, Fusion Sci. and Tech. 61 (2012) 144-149.

[17]. J.K. Fink, Thermalphysical properties of uranium dioxide, J. Nucl. Mater. 279 (2000) 1-18. 
[18]. H.S. Kim, C.Y. Joung, B.H. Lee, J.Y. Oh, Y.H. Koo, P. Heimgartner, Applicability of $\mathrm{CeO} 2$ as a surrogate for $\mathrm{PuO} 2$ in a $\mathrm{MOX}$ fuel development, J. Nucl. Mater. 378 (2008) 98-104.

[19]. K. Wheeler, P. Peralt, M. Parra, K. McClellan, J. Dunwoody, G. Egeland, Effect of sintering conditions on the microstructure and mechanical properties of $\mathrm{ZrN}$ as a surrogate for actinide nitride fuels, J. Nucl. Mater. 366 (2007) 306-316.

[20]. D.R. Lide, Handbook of chemistry and physics. 87 ed. Boca Raton: CRC Press, 1998.

[21]. B. Ma, Nuclear reactor materials and applications, New York: Van Nostrand Reinhold Co., 1983.

[22]. B.R.T. Frost, The carbides of uranium, J. Nucl. Mater. 4 (1963) 265-300.

[23]. R. Edwin, Air force materials laboratory report AFML-TR-69-117, Part VII, 1970

[24]. V.N. Lipatnikov, A.L. Gusev, P. Ettmayer, W. Lengauer, Phase transformations in non-stoichiometric vanadium carbide, J. Phys. Condens. Matter. 11 (1999) 163-184.

[25]. H.O. Pierson, Handbook of refractory carbides and nitrides, Westwood: William Andrew Publishing, 1996.

[26]. D. Guintini, X. Wei, A.L. Maximenko, W. Li, E.A. Olevsky, Initial state of free pressureless spark-plasma sintering of vanadium carbide: determination of surface diffusion parameters, Int. J. Refract. Met. and Hard Mater. 41 (2013) 501-506.

[27]. D.J. Willis, J.S.H. Lake, Measurement of grain size using the circle intercept method, Scripta Metall. 21 (1987) 1733-1736.

[28]. ASTM C1499 - 09 Standard test method for monotonic equibiaxial flexural strength of advanced ceramics at ambient temperature.

[29]. D. Lahiri, E. Khaleghi, S.R. Bakshi, W. Li, E.A. Olevsky, A. Agarwal, Graphene-induced srengthening in spark plasma sintered tantalum carbide-nanotube composite, Scripta Mater. 68 (2013) 285-288.

[30]. E.A. Olevsky, Theory of sintering: from discrte to continuum, Mater. Sci. \& Eng. R. 23 (1998) 41-100.

[31]. J. Murain, V. Komps, V. Kuts, Computational modeling and advanced simulations, Netherlands: Springer, 2011. 
[32]. C. Degueldre, P. Tissot, H. Lartigue, M. Pouchon, Specific heat capacity and debye temperature of zirconia and its solid solution, Thermochim. Acta 403 (2003) 267-273.

[33]. R.M. German, Sintering theory and practice, New York: John Wiley \& Sons, 1996.

[34]. R.M. German, J. Ma, X. Wang, E. Olevsky, Processing model for tungsten powders and extension to nanoscale size range, Powder metallurgy 49, (2006) 19-27

[35]. G.J. Snyder, E.S. Toberer, Complex thermoelectric materials. Nat. Mater. 7 (2008) 105-114.

[36]. E. Khaleghi, Y.S. Lin, M.A. Meyers, E.A. Olevsky, Spark plasma sintering of tantalum carbide, Scripta Mater. 63 (2010) 577-580.

[37]. E.A. Olevsky, E.R. Strutt, M.A. Meyers, Combustion synthesis and quasiisostatic densification of powder cermets, J. Mater. Proc. Techn. 121 (2002) 157-166 
TABLE CAPTIONS

Table 1. Desired Basic Properties for Carbide Based Nuclear Fuel Pellet According to General Atomics Design

Table 2. Vanadium Carbide and Uranium Carbide Physical Properties at 250C: Comparison20-,21,22,23,24,25

Table 3. Vanadium Carbide Powder Characteristics

Table 4. SPS Consolidation Results for VC Powder Processed with $100^{\circ} \mathrm{C} / \mathrm{min}$ Heating Rate

Table 5. Satisfactory SPS Consolidation Parameters and Obtained Surrogate Properties 
Table 1. Desired Basic Properties for Carbide Based Nuclear Fuel Pellet According to General Atomics Design

\begin{tabular}{ll}
\hline Key Property & Range \\
\hline Porosity & $20 \%$ to $30 \%$ \\
Strength at about $800^{\circ} \mathrm{C}$ & $>60 \mathrm{MPa}$ \\
Thermal conductivity at about $800^{\circ} \mathrm{C}$ & $>13.8 \mathrm{~W} /(\mathrm{m} . \mathrm{K})$ \\
\hline
\end{tabular}

Table 2. Vanadium Carbide and Uranium Carbide Physical Properties at $25^{\circ} \mathrm{C}$ :

Comparison $^{20-25}$

\begin{tabular}{llrr}
\hline Property $\backslash$ Material & Unit & Vanadium Carbide & Uranium Carbide \\
\hline Chemical Formula & & $\mathrm{V}_{8} \mathrm{C}_{7}$ & $\mathrm{UC}$ \\
Crystal Structure & & cubic, cF8 & cubic, cF8 \\
Space Group & & $\mathrm{Fm} \overline{3} \mathrm{~m}, \mathrm{No} .225$ & $\mathrm{Fm} \overline{3} \mathrm{~m}$, No. 225 \\
Density & {$\left[\mathrm{g} / \mathrm{cm}^{3}\right]$} & 5.77 & 13.63 \\
Molar Mass & {$\left[\mathrm{g} / \mathrm{mol}^{3}\right]$} & 62.95 & 250.04 \\
Bulk Modulus & {$[\mathrm{GPa}]$} & 683 & 147 \\
Shear Modulus & {$[\mathrm{GPa}]$} & 228 & 80 \\
Heat Capacity - Mass & {$[\mathrm{J} / \mathrm{g} / \mathrm{K}]$} & 0.530 & 0.202 \\
Heat Capacity - Volume & {$[\mathrm{J} / \mathrm{cm} / \mathrm{K}]$} & 3.058 & 2.753 \\
Heat Capacity - Mole & {$[\mathrm{J} / \mathrm{mol} / \mathrm{K}]$} & 33 & 51 \\
Thermal Conductivity & {$[\mathrm{W} / \mathrm{m} / \mathrm{K}]$} & 39 & 19 \\
CTE & {$\left[10^{-6} / \mathrm{K}\right]$} & 7.20 & 0.12 \\
Melting Temperature & {$[\mathrm{K}]$} & 3083 & 2660 \\
Electrical Conductivity & {$[\mu \Omega / \mathrm{cm}]$} & 37 & 60 \\
\hline
\end{tabular}


Table 3. Vanadium Carbide Powder Characteristics

\begin{tabular}{lr}
\hline Carbide Powder & $\begin{array}{r}\text { Vanadium } \\
\text { Carbide }\end{array}$ \\
\hline Vendor & $\begin{array}{c}\text { Asian Light } \\
\text { VC120206 } \\
\text { Designation (lot) }\end{array}$ \\
Purity & $>99 \%$ \\
Fabrication Method & Dry Ball Milled \\
Particle Size $(\mu \mathrm{m})$ & \\
$D_{10}$ & 26 \\
$D_{50}$ & 232 \\
$D_{90}$ & 533 \\
Tap Density $\left(\mathrm{g} / \mathrm{cm}^{3}\right)$ & $(34.1 \%$ TD) 1.97 \\
Theoretical Density & 5.77 \\
$\left(\mathrm{~g} / \mathrm{cm}^{3}\right)$ & 3083 \\
Melting Temperature $[\mathrm{K}]$ & \\
\hline
\end{tabular}


Table 4. SPS Consolidation Results for VC Powder Processed with $100^{\circ} \mathrm{C} / \mathrm{min}$ Heating Rate Temperature $\left[{ }^{\circ} \mathrm{C}\right]$ Stress $[\mathrm{MPa}]$ Time $[\mathrm{min}]$ Relative Density $( \pm 0.5 \%)$

\begin{tabular}{|c|c|c|c|}
\hline \multirow{7}{*}{1100} & \multirow{3}{*}{20} & 5 & $57.5 \%$ \\
\hline & & 10 & $60.3 \%$ \\
\hline & & 30 & $61.7 \%$ \\
\hline & 25 & 10 & $62.4 \%$ \\
\hline & \multirow[b]{2}{*}{60} & 5 & $64.4 \%$ \\
\hline & & 15 & $67.8 \%$ \\
\hline & 75 & 5 & $68.5 \%$ \\
\hline \multirow{3}{*}{1200} & 20 & 10 & $65.5 \%$ \\
\hline & 25 & 10 & $65.1 \%$ \\
\hline & 60 & 5 & $70.2 \%$ \\
\hline \multirow{7}{*}{1300} & \multirow{2}{*}{20} & 5 & $67.1 \%$ \\
\hline & & 15 & $68.0 \%$ \\
\hline & 25 & 5 & $68.4 \%$ \\
\hline & \multirow{3}{*}{60} & 10 & $75.0 \%$ \\
\hline & & 15 & $77.2 \%$ \\
\hline & & 30 & $79.5 \%$ \\
\hline & 75 & 10 & $79.2 \%$ \\
\hline \multirow{3}{*}{1400} & 20 & 5 & $69.7 \%$ \\
\hline & 60 & 10 & $80.1 \%$ \\
\hline & 75 & 30 & $84.3 \%$ \\
\hline
\end{tabular}


Table 5. Satisfactory SPS Consolidation Parameters and Obtained Surrogate Properties

\begin{tabular}{|c|c|c|c|c|c|c|}
\hline Property $\backslash$ Density and SPS & 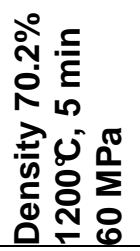 & 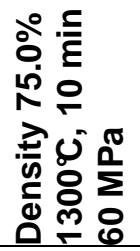 & 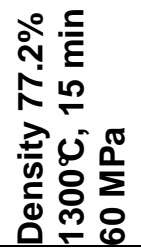 & 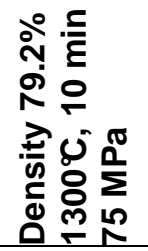 & 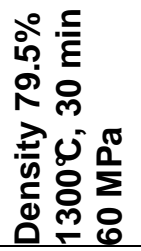 & 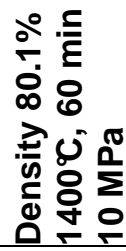 \\
\hline Porosity at $25^{\circ} \mathrm{C}, 1 \mathrm{~atm}$ & $29.8 \%$ & $25.0 \%$ & $22.8 \%$ & $20.8 \%$ & $20.5 \%$ & $19.9 \%$ \\
\hline $\begin{array}{l}\text { Extrapolated } \\
\text { Open Porosity } \\
\text { at } 25^{\circ} \mathrm{C}, 1 \mathrm{~atm}\end{array}$ & $26.7 \%$ & $22.4 \%$ & $20.4 \%$ & $18.6 \%$ & $18.4 \%$ & $17.8 \%$ \\
\hline $\begin{array}{l}\text { Extrapolated } \\
\text { Permeability } \\
\text { at } 25^{\circ} \mathrm{C} \text { [Darcy] }\end{array}$ & 0.0069 & 0.0043 & 0.0034 & 0.0028 & 0.0027 & 0.0026 \\
\hline TRS @ 25 [MPa] & 112 & 164 & 188 & 209 & 213 & 219 \\
\hline $\begin{array}{l}\text { Extrapolated } \\
\text { Hardness } \\
\text { at } 25^{\circ} \mathrm{C}, 1 \text { atm }\end{array}$ & 72 & 81 & 79 & 77 & 77 & 76 \\
\hline $\begin{array}{l}\text { Extrapolated } \\
\text { Heat Capacity } \\
\text { at } 80^{\circ} \mathrm{C}, 1 \text { atm }[\mathrm{J} /(\mathrm{cc} . \mathrm{K})]\end{array}$ & 3.51 & 3.66 & 3.73 & 3.79 & 3.80 & 3.82 \\
\hline $\begin{array}{l}\text { Extrapolated } \\
\text { Thermal Conductivity } \\
\text { at } 800^{\circ} \mathrm{C}, 1 \text { atm }[\mathrm{W} /(\mathrm{m} . \mathrm{K})]\end{array}$ & 15.8 & 16.0 & 16.4 & 17.2 & 17.3 & 17.7 \\
\hline
\end{tabular}




\section{FIGURE CAPTIONS}

Figure 1. Schematic of EM2 Fuel in Which the UC Fuel is Formed by Sintering of Spherical Kernels

Figure 2. Agglomerated Vanadium Carbide Powder, (a) 100X-Scale Bar $500 \mu \mathrm{m}$;

(b) $5000 X-S c a l e ~ B a r ~ 10 \mu \mathrm{m}$; (c) 1000X-Scale Bar $50 \mu \mathrm{m}$

Figure 3. Vanadium Carbide Powder Particle Size Distribution

Figure 4. XRD Scanning of Vanadium Carbide Powder (V8C7 Ref. Code 00023-1468)

Figure 5. SPS Tooling and Pellet Configurations, Interfaces between Pellet, Punches, and Die Wrapping with a Layer of Graphite Foil of $0.40 \mathrm{~mm}$ (Drawn in Scale)

Figure 6. Relative Density vs. Temperature for $1100{ }^{\circ} \mathrm{C}$ Consolidation Temperature with Corresponding Fracture Surfaces

Figure 7. Densification Kinetics for $60 \mathrm{MPa}$

Figure 8. Relative Density versus (a) Temperature, (b) Pressure, and (c) Time for SPS Processed Vanadium Carbide Pellets

Figure 9. Cross Sectional Surface (1000X Magnification) of VC Powder Consolidated under Different Conditions (a) $1100^{\circ} \mathrm{C}, 75 \mathrm{MPa}, 5 \mathrm{~min}$ with $69.7 \%$ Density; (b) $1300^{\circ} \mathrm{C}, 60 \mathrm{MPa}, 30$ min - with $79.5 \%$ Density; (c) $1400^{\circ} \mathrm{C}, 75 \mathrm{MPa}, 30 \mathrm{~min}$ - with $84.3 \%$ Density

Figure 10. Cross Sectional Surface of $1300^{\circ} \mathrm{C}, 60 \mathrm{MPa}, 30 \mathrm{~min}$ - with $79.8 \%$ Density; (a) by SEM; (b) by Electron Backscatter Diffraction

Figure 11. Vanadium Carbide 84.3\% Dense Pellet and Powder XRD Scanning Results Comparison

Figure 12. Open Porosity versus Relative Density for SPS-fabricated VC Pellets

Figure 13. Permeability versus Relative Density for SPS VC Pellets

Figure 14. Transverse Rupture Strength (TRS) versus Relative Density for SPS VC Pellet and Literature Reported TRS for TaC Specimen [36]

Figure 15. Scale A Rockwell Hardness versus Relative Density for SPSproduced Vanadium Carbide Pellet

Figure 16. Constant Pressure Specific s Heat Capacity versus Temperature for SPS-fabricated Vanadium Carbide Pellets with Different Relative Density and the Bulk Vanadium Carbide Reference Curve [24] 
Figure 17. Thermal Conductivity versus Temperature for SPS-fabricated Vanadium Carbide Pellets with Different Relative Density 
Figure 1. Schematic of $\mathrm{EM}^{2}$ Fuel in Which the UC Fuel is Formed by Sintering of Spherical Kernels 

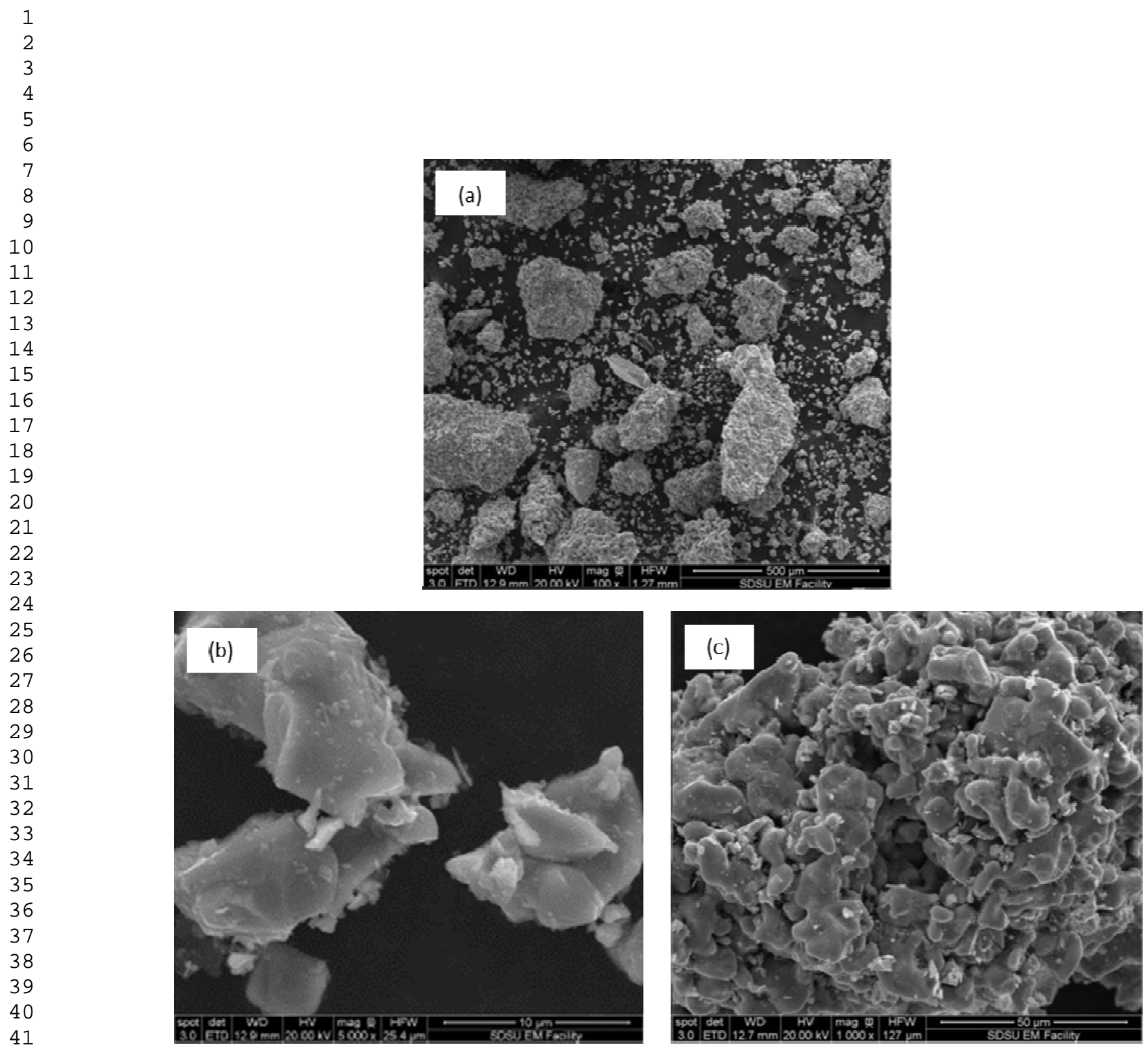

Figure 2. Agglomerated Vanadium Carbide Powder, (a) 100X-Scale Bar 500 m; (b) $5000 X-$ Scale Bar $10 \mu \mathrm{m}$; (c) 1000X-Scale Bar $50 \mu \mathrm{m}$ 


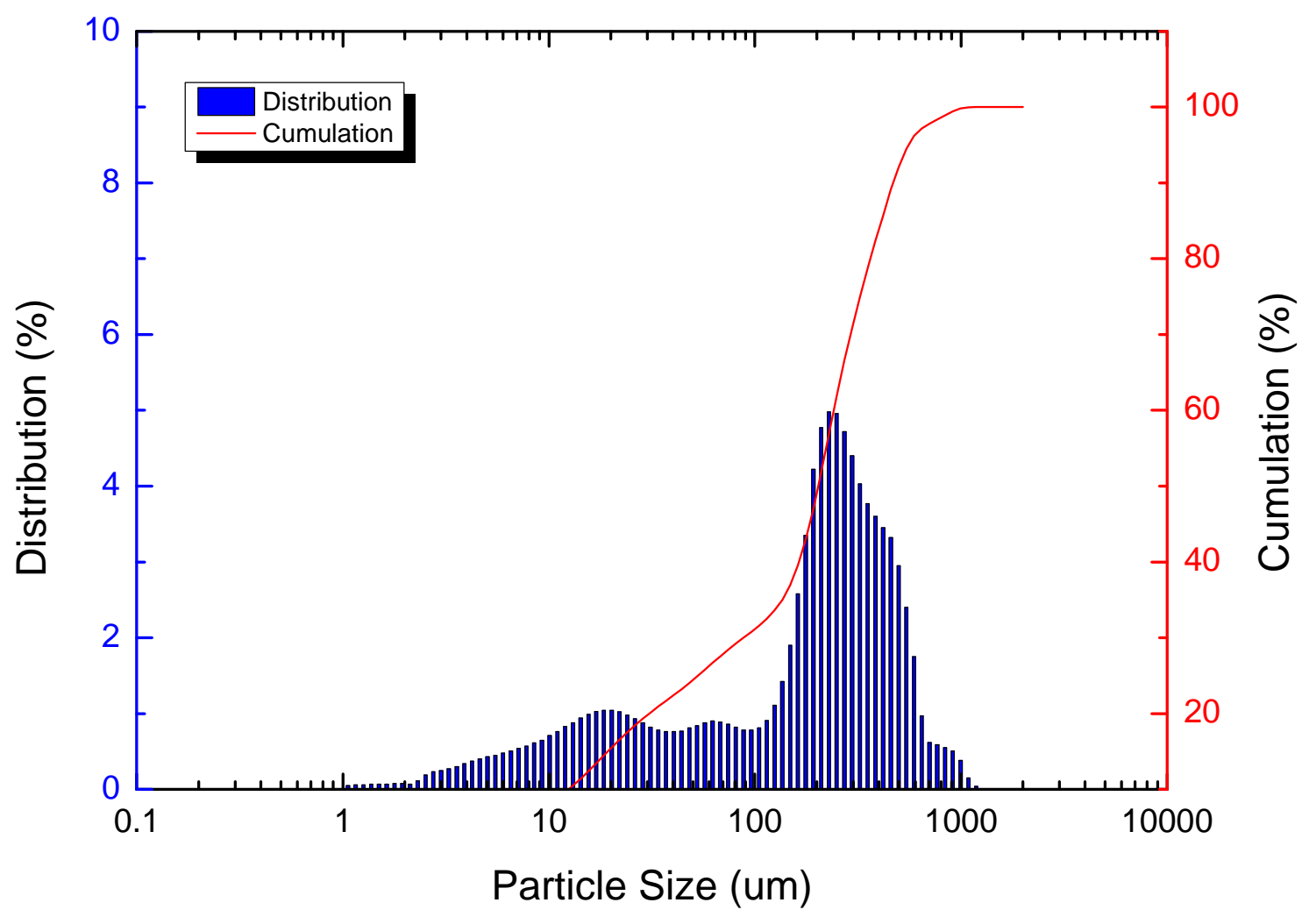

Figure 3. Vanadium Carbide Powder Particle Size Distribution 


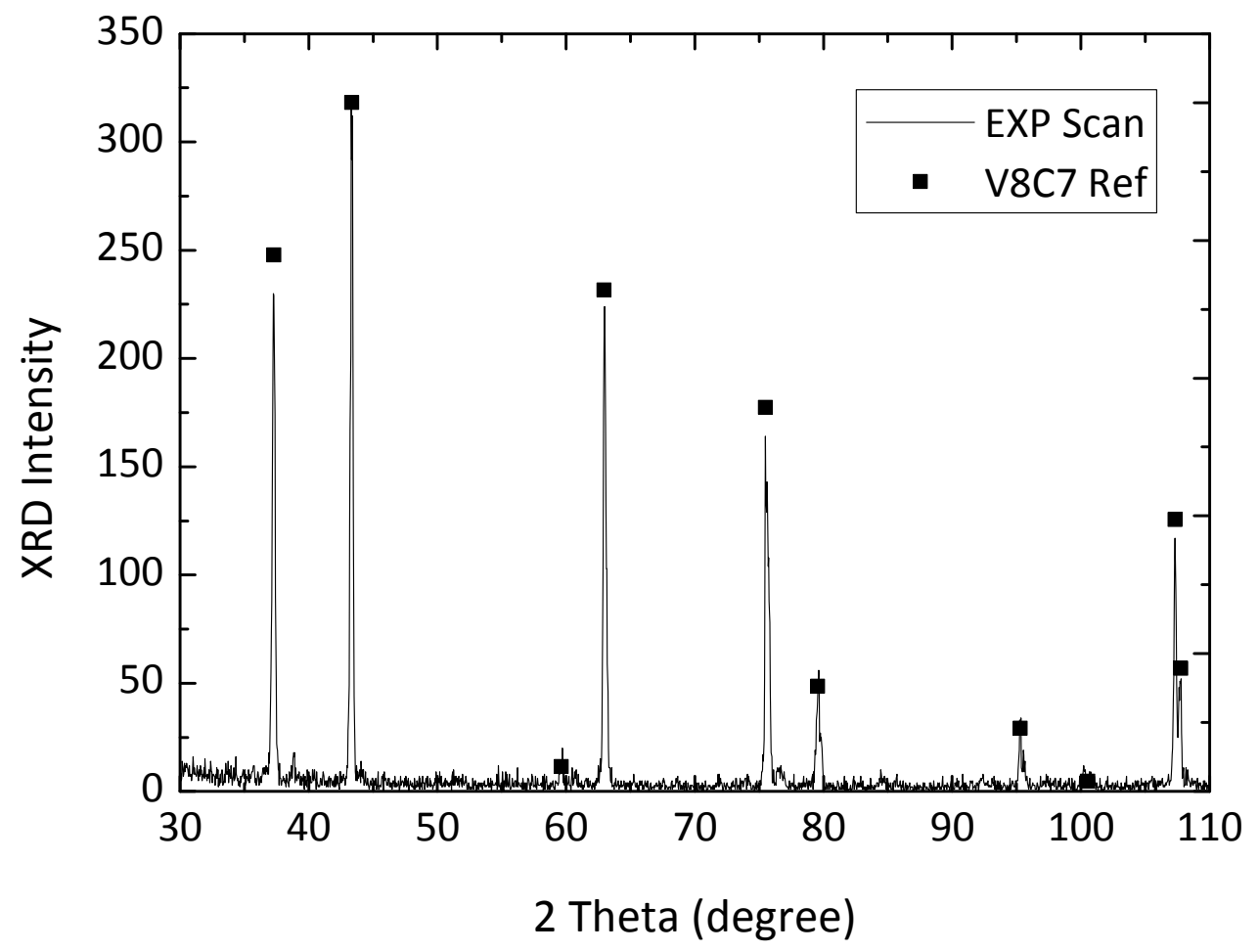

Figure 4. XRD Scanning of Vanadium Carbide Powder $\left(\mathrm{V}_{8} \mathrm{C}_{7}\right.$ Ref. Code 00-023-1468) 
Figure 5. SPS Tooling and Pellet Configurations, Interfaces between Pellet, Punches, and Die Wrapping with a Layer of Graphite Foil of $0.40 \mathrm{~mm}$ (Drawn in Scale) 


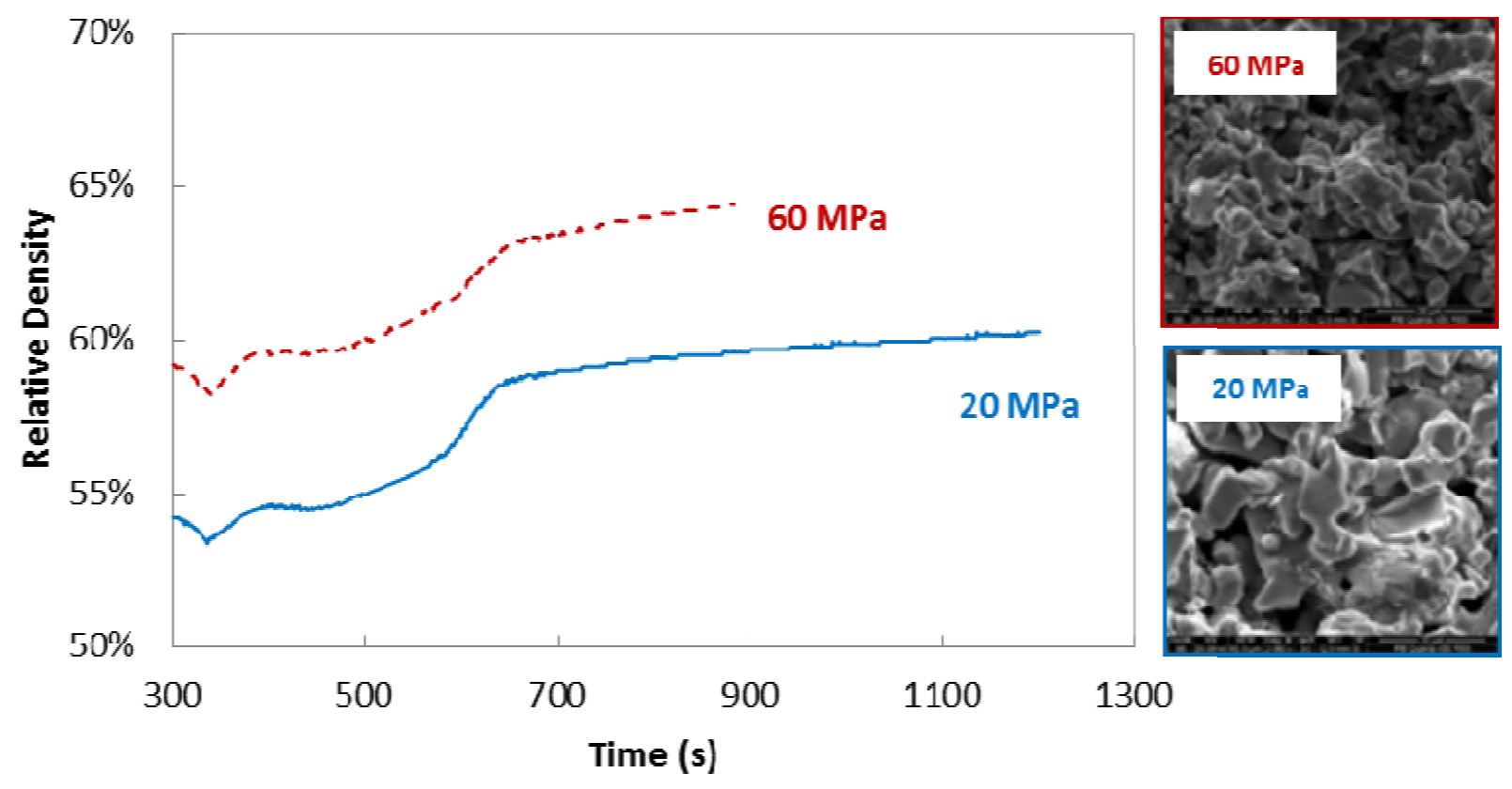

Figure 6. Relative Density vs. Temperature for $1100^{\circ} \mathrm{C}$ Consoli dation Temperature with Corresponding Fracture Surfaces 


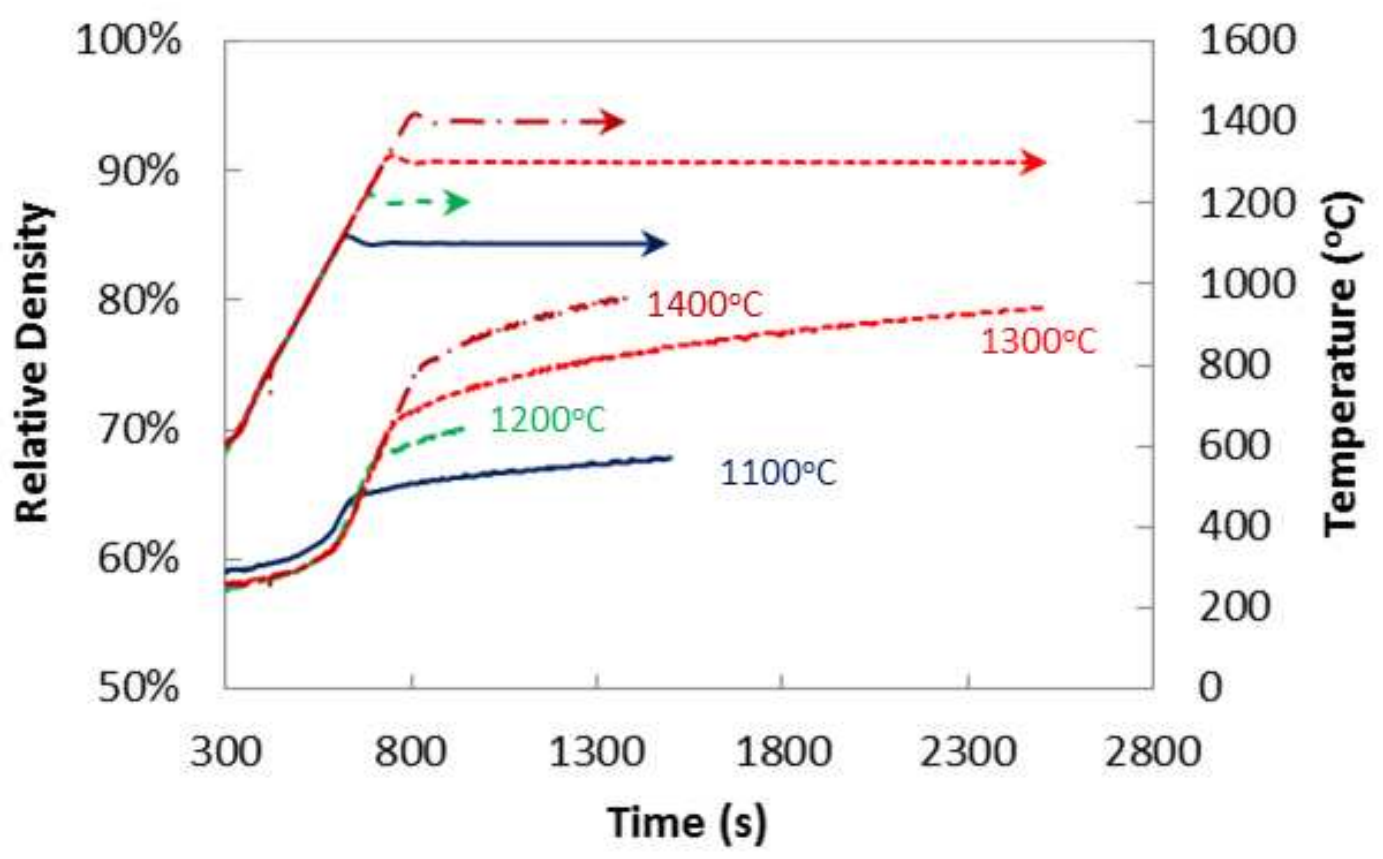

Figure 7. Densification Kinetics for $60 \mathrm{MPa}$ 

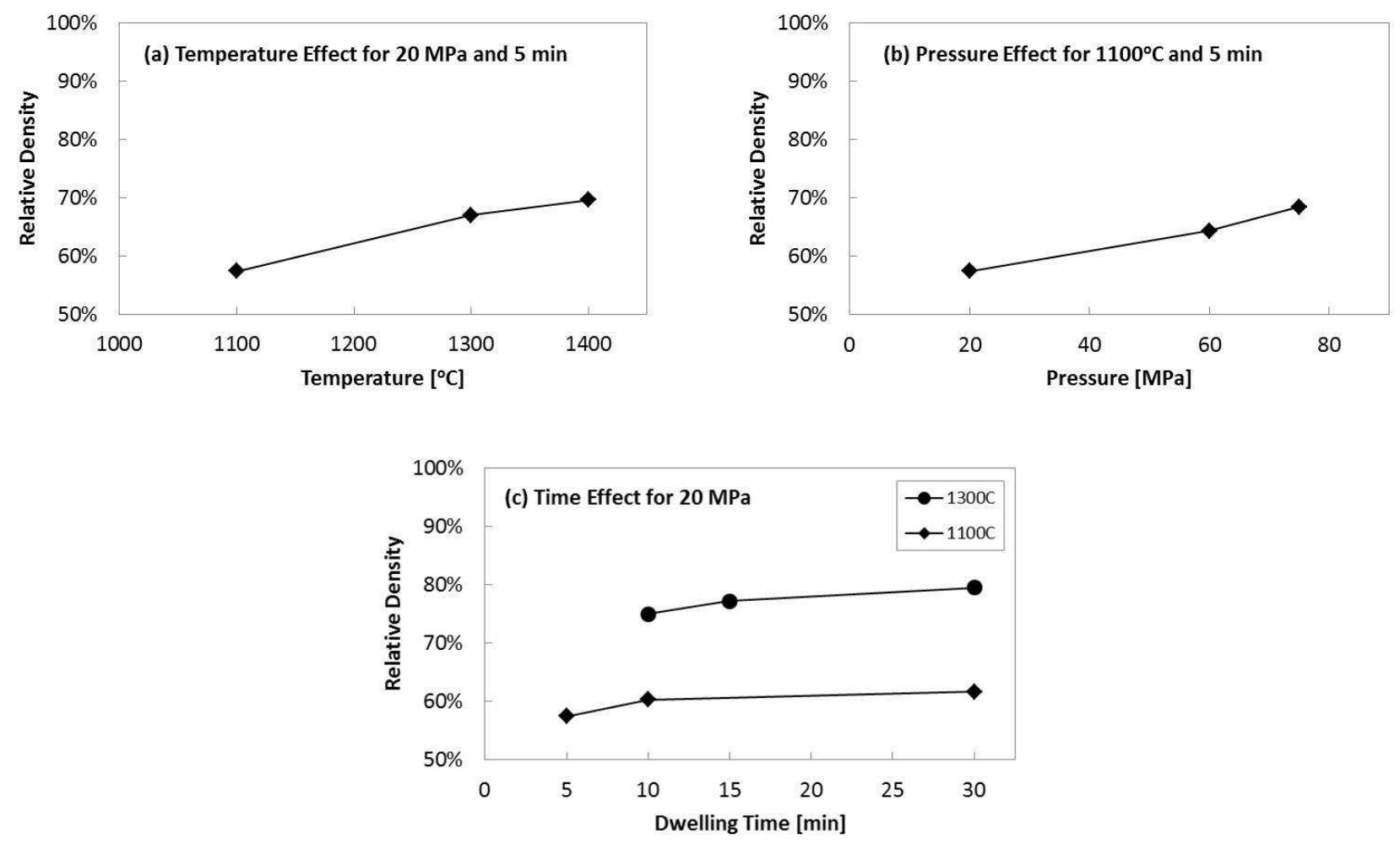

Figure 8. Relative Density versus (a) Temperature, (b) Pressure, and (c) Time for SPS Processed Vanadium Carbide Pellets 

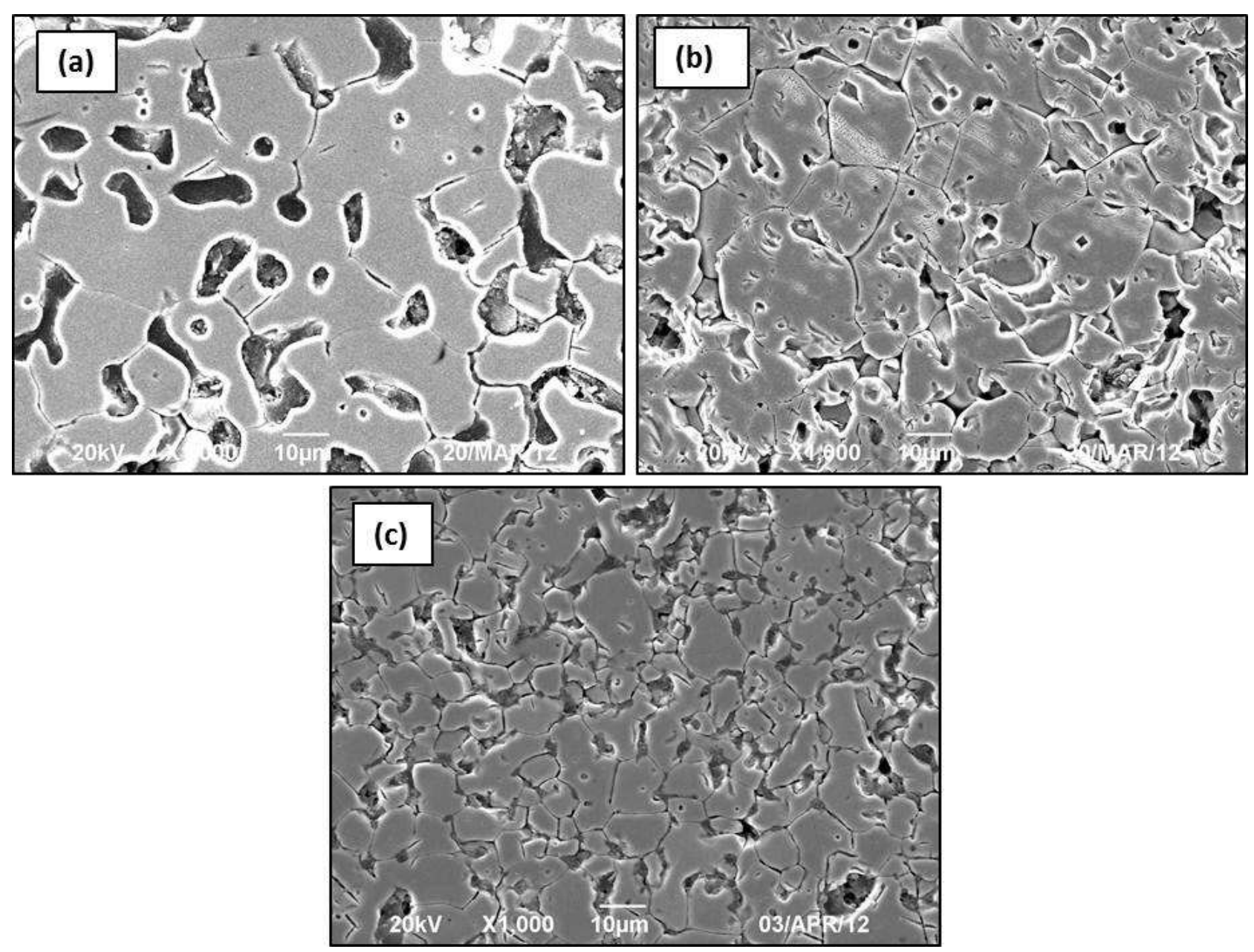

Figure 9. Cross Sectional Surface (1000X Magnification) of VC Powder Consolidated under Different Conditions (a) $1100^{\circ} \mathrm{C}, 75 \mathrm{MPa}, 5 \mathrm{~min}$ - with $69.7 \%$ Density; (b) $1300^{\circ} \mathrm{C}, 60 \mathrm{MPa}, 30$ min - with $79.5 \%$ Density; (c) $1400^{\circ} \mathrm{C}, 75 \mathrm{MPa}, 30 \mathrm{~min}$ - with $84.3 \%$ Density 

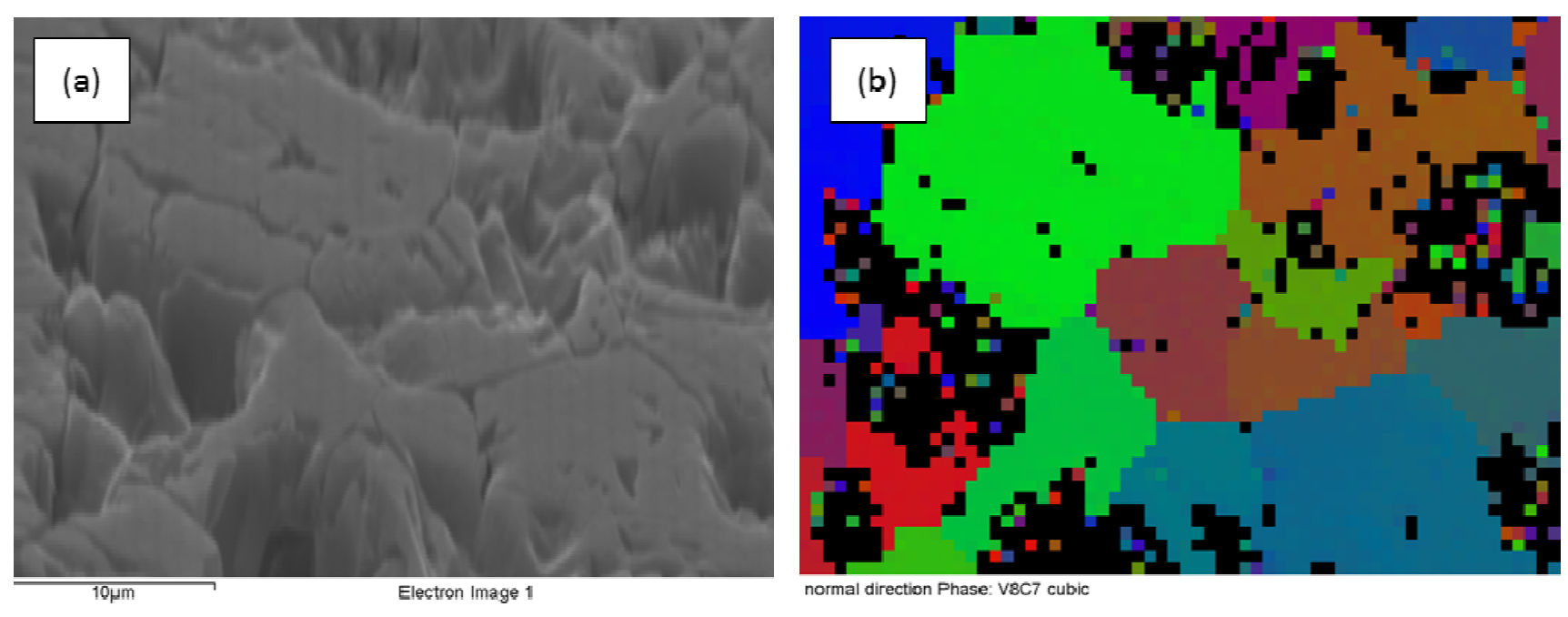

Figure 10. Cross Sectional Surface of $1300^{\circ} \mathrm{C}, 60 \mathrm{MPa}, 30 \mathrm{~min}$ - with $79.8 \%$ Density; (a) by SEM; (b) by Electron Backscatter Diffraction 


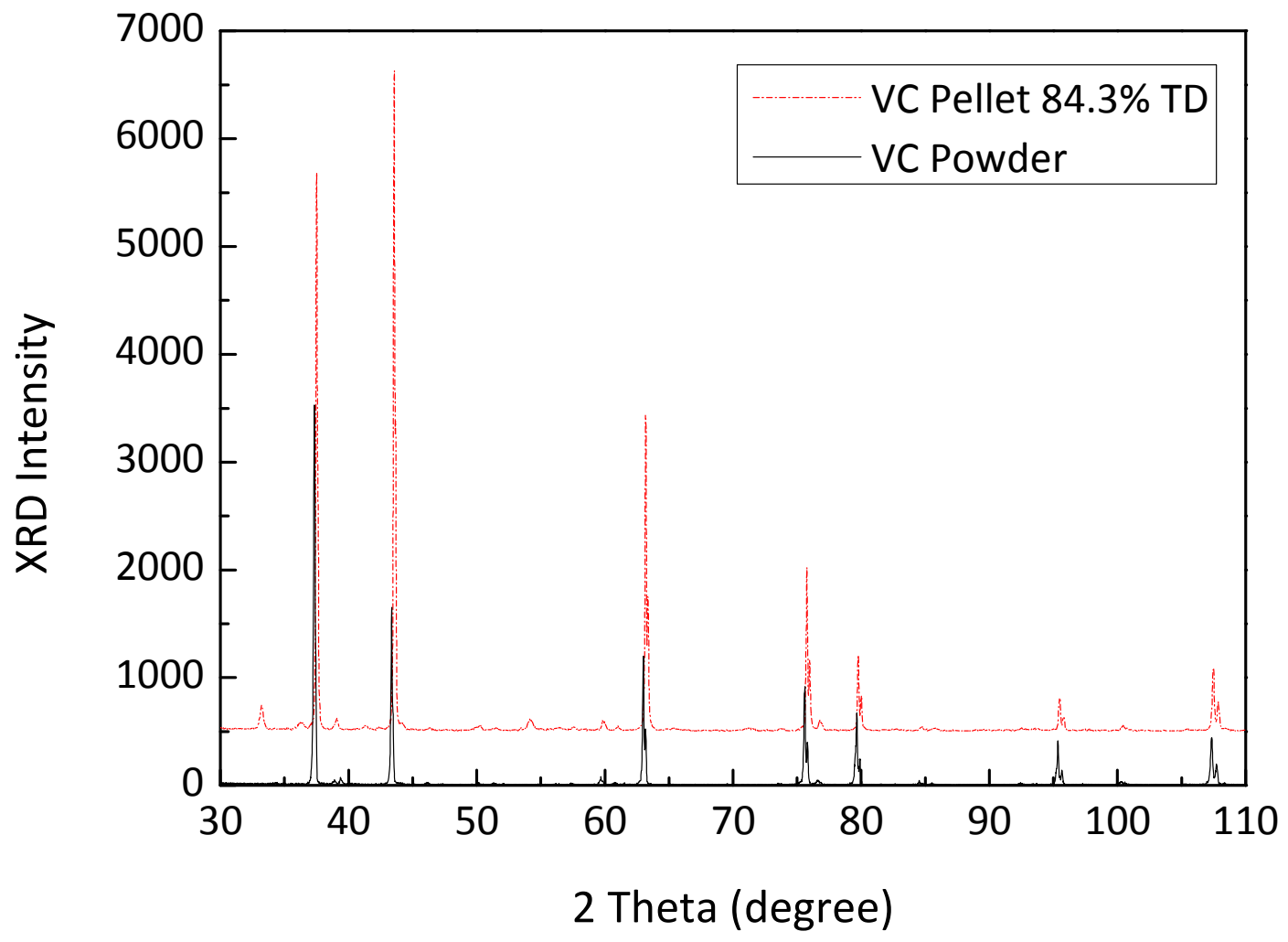

Figure 11. Vanadium Carbide 84.3\% Dense Pellet and Powder XRD Scanning Results Comparison 


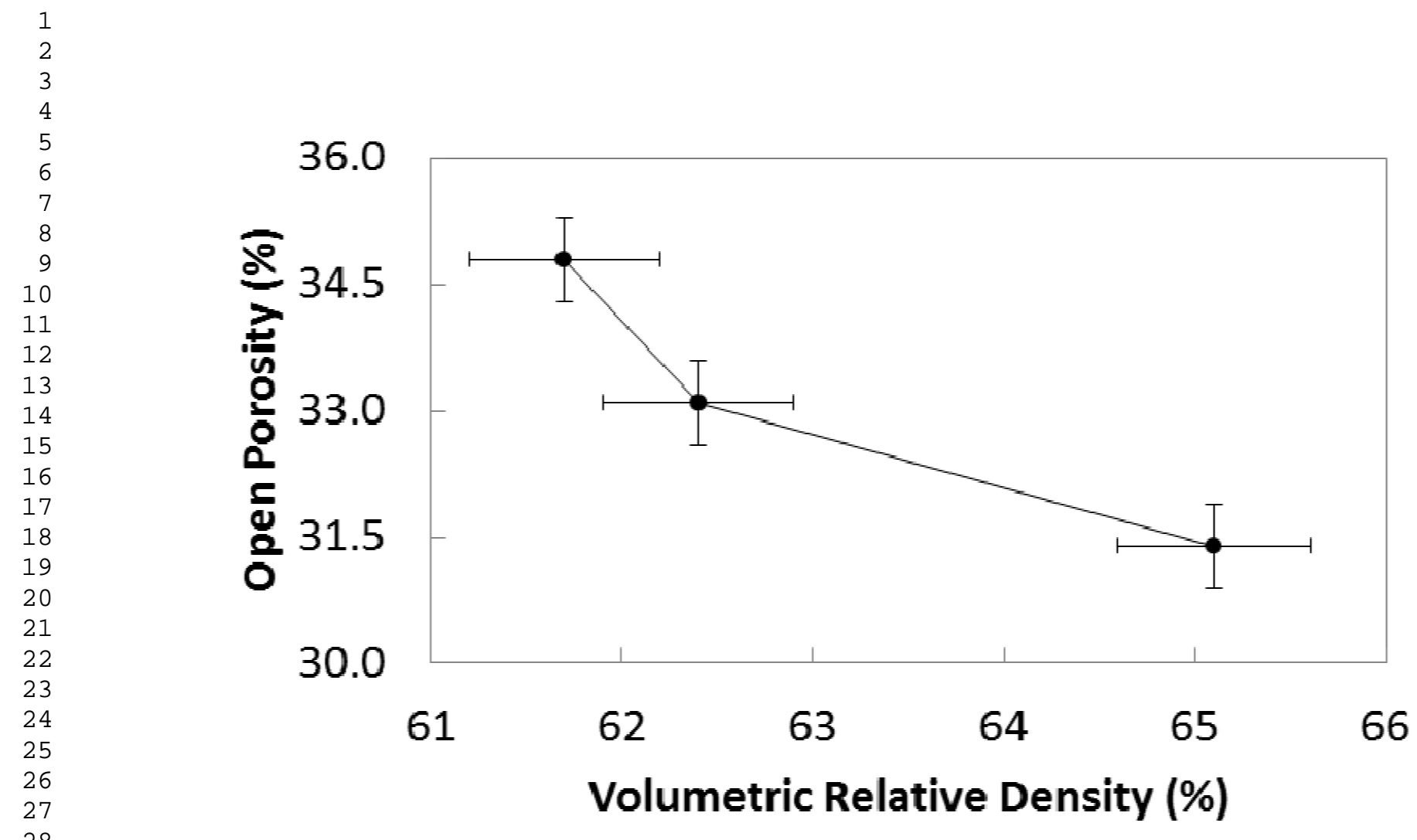

Figure 12. Open Porosity versus Relative Density for SPS-fabricated VC Pellets 


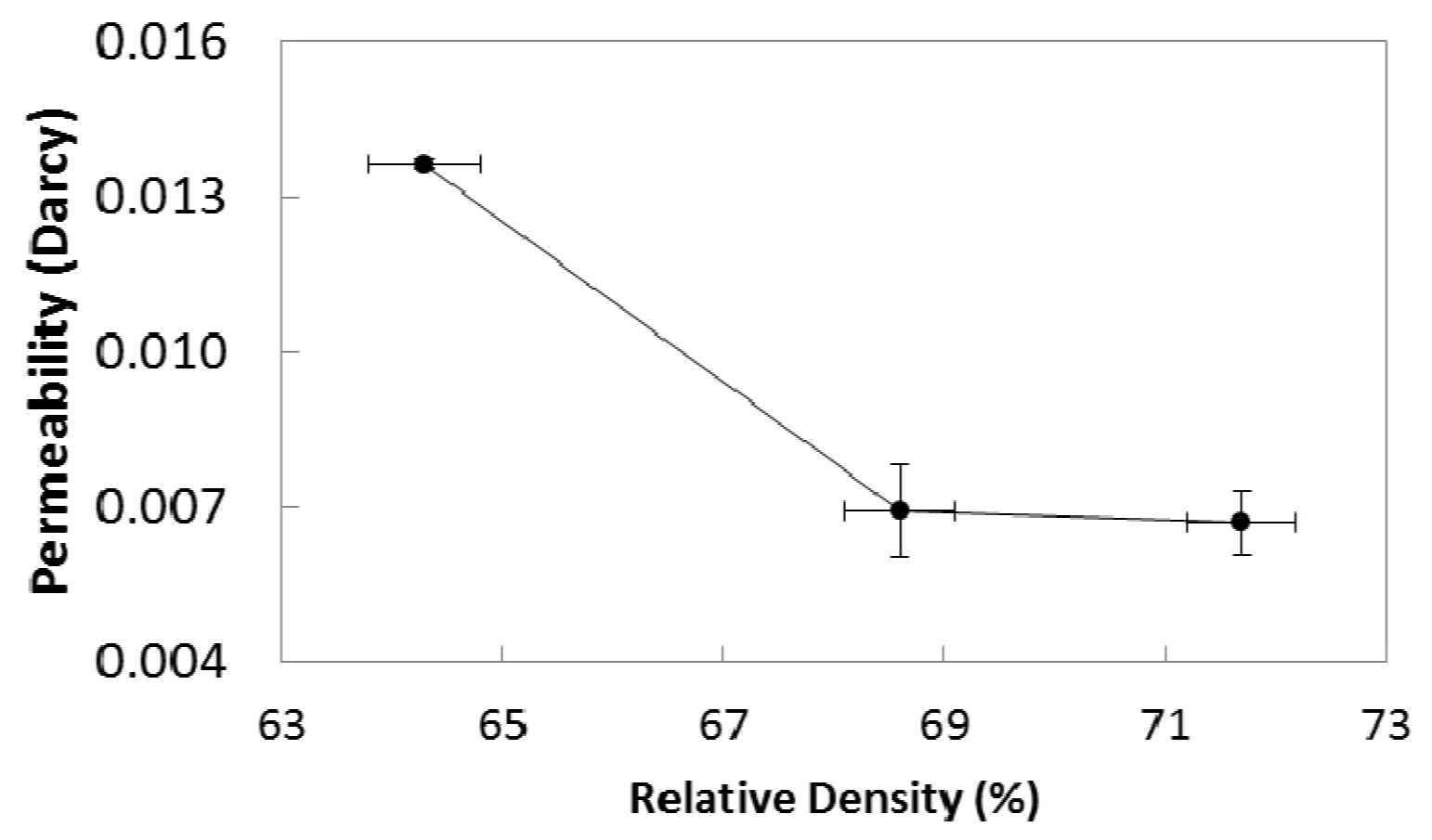

Figure 13. Permeability versus Relative Density for SPS VC Pellets 


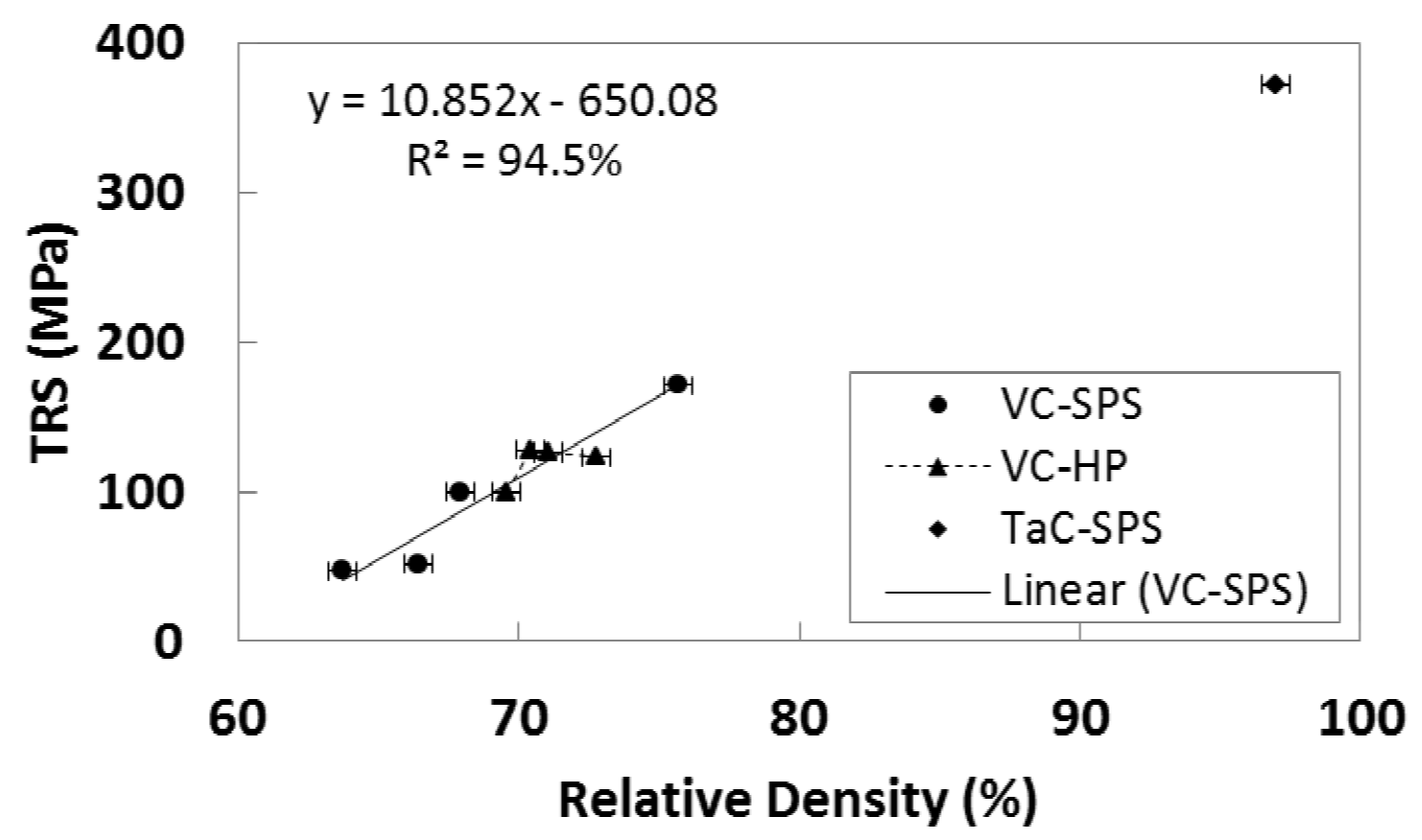

Figure 14. Transverse Rupture Strength (TRS) versus Relative Density for SPS VC Pellet and Literature Reported TRS for TaC Specimen [36] 


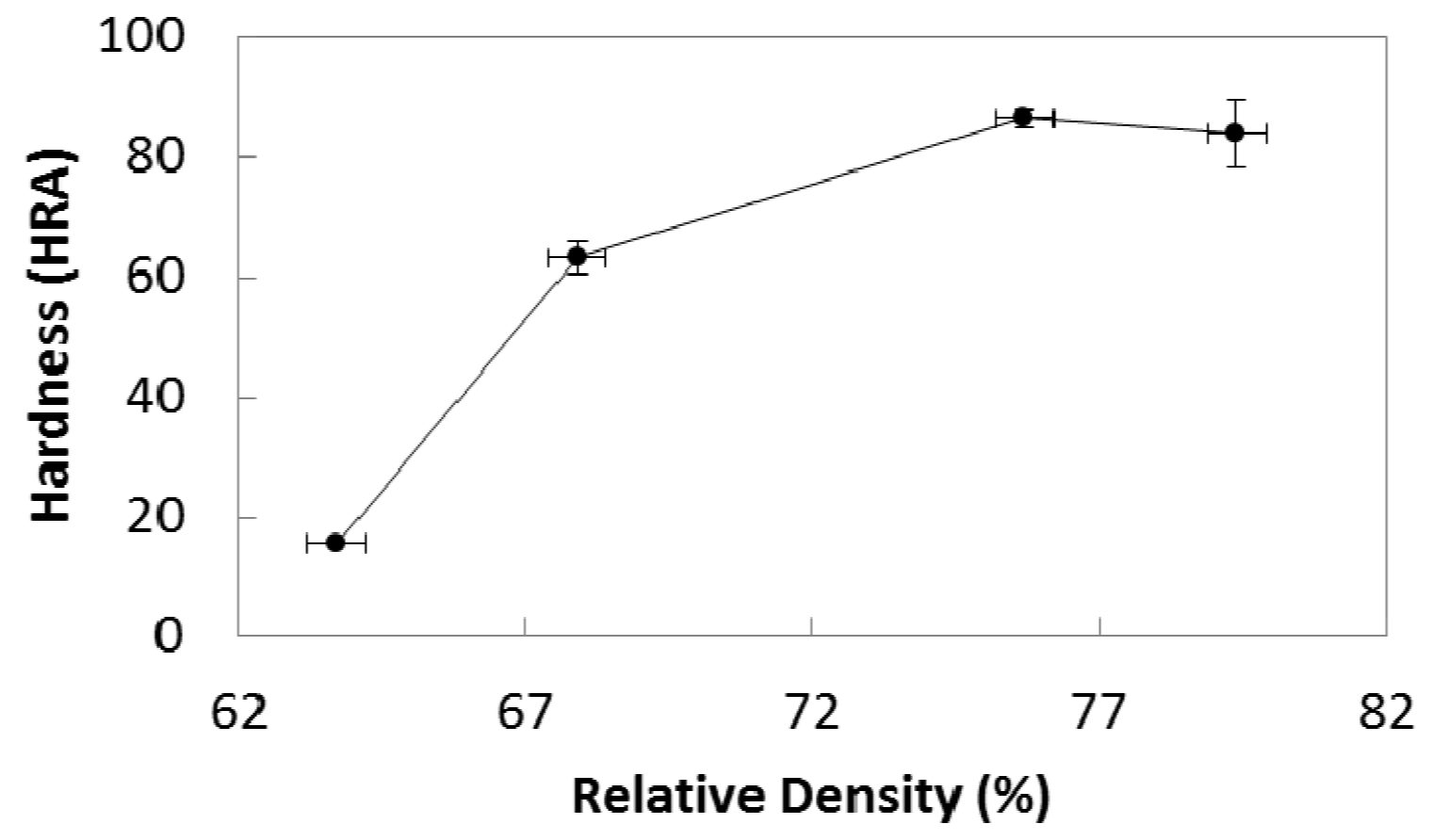

Figure 15. Scale A Rockwell Hardness versus Relative Density for SPS-produced Vanadium Carbide Pellet 


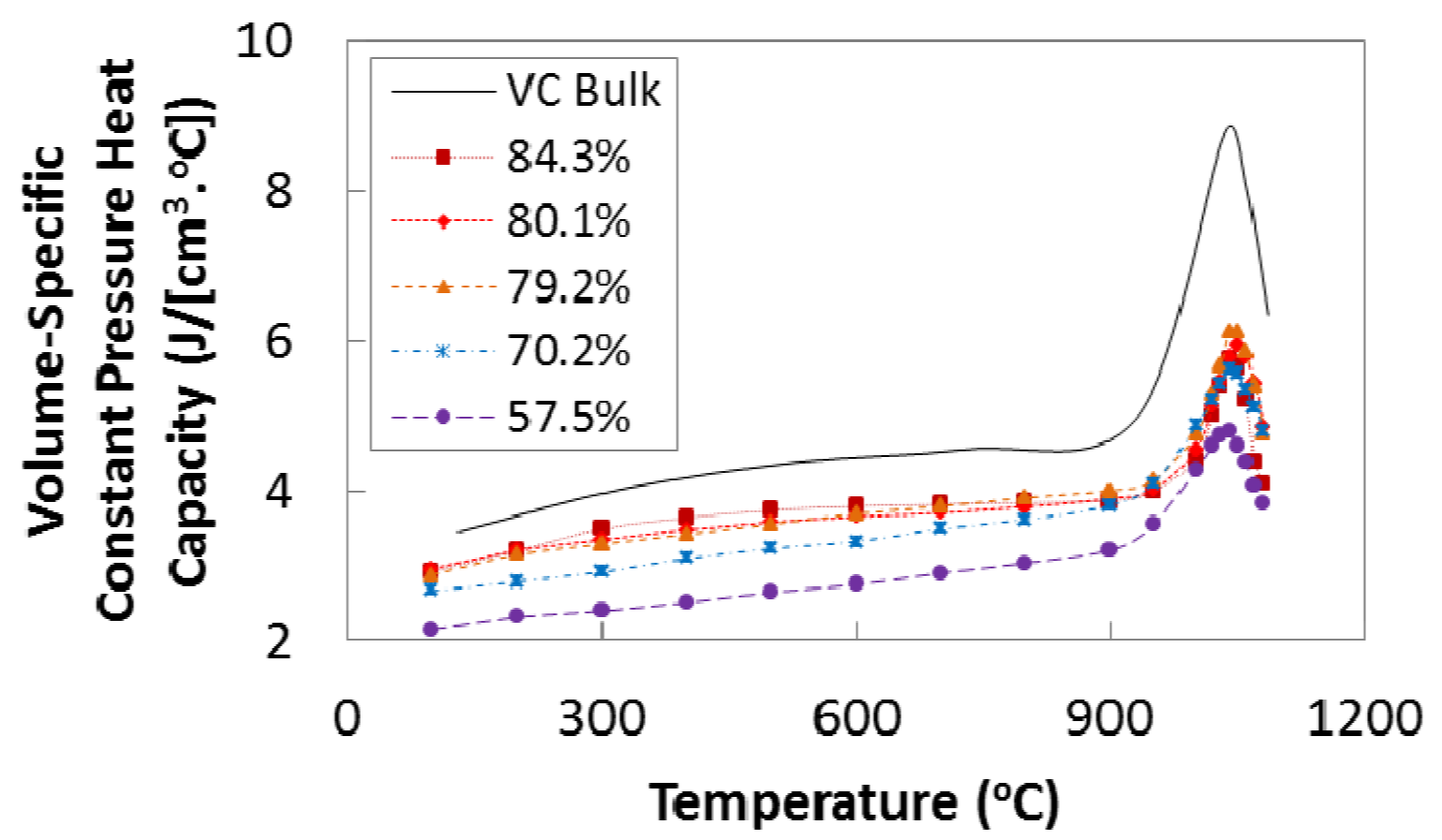

Figure 16. Constant Pressure Specific s Heat Capacity versus Temperature for SPSfabricated Vanadium Carbide Pellets with Different Relative Density and the Bulk Vanadium Carbide Reference Curve [24] 


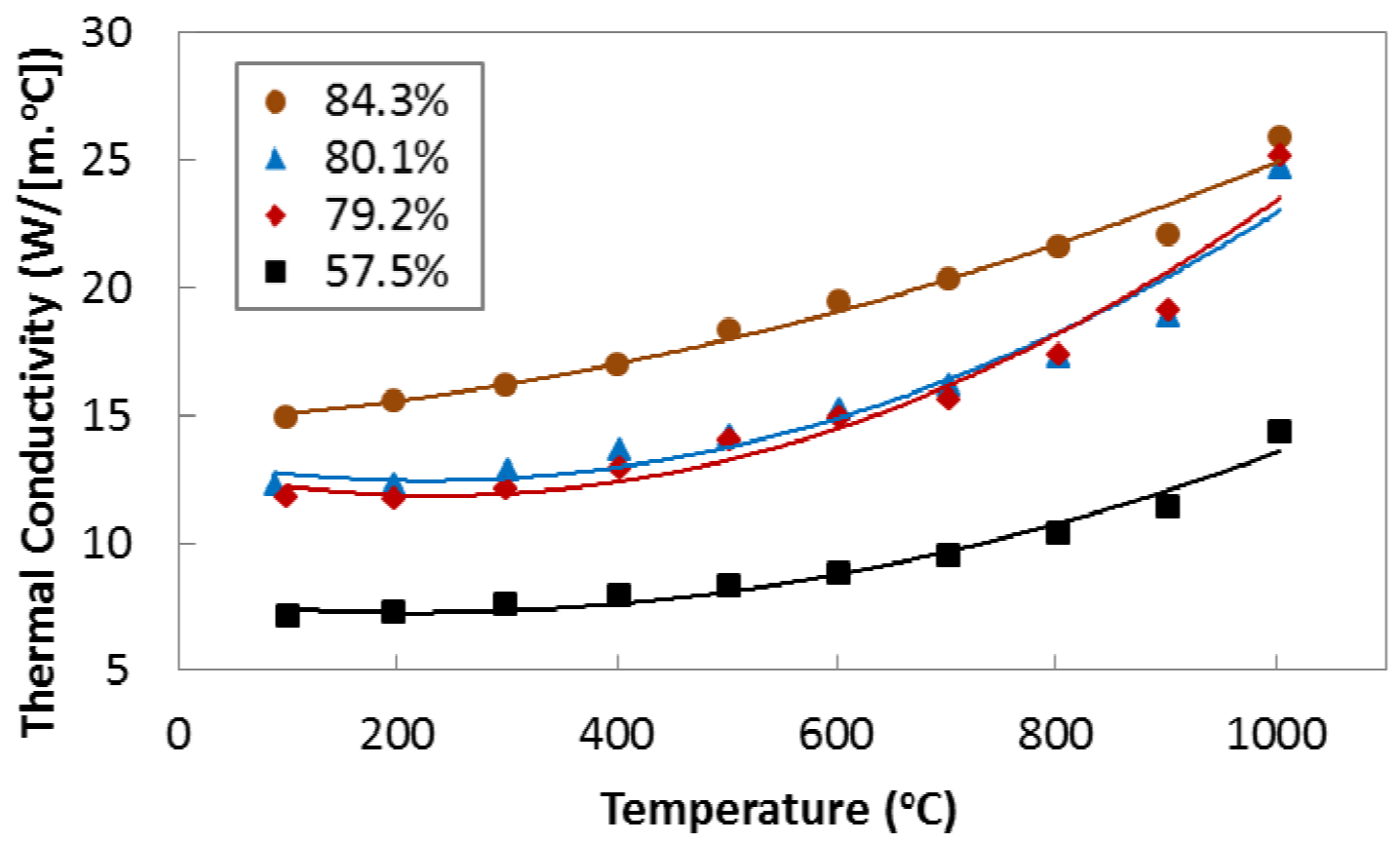

Figure 17. Thermal Conductivity versus Temperature for SPS-fabricated Vanadium Carbide Pellets with Different Relative Density 